Article

\title{
Powering Jobs: The Employment Footprint of Decentralized Renewable Energy Technologies in Sub Saharan Africa
}

\author{
Rebekah Shirley ${ }^{1,2, *}$, Chih-Jung Lee ${ }^{1}$, Hope Nyambura Njoroge ${ }^{2}$, \\ Sarah Odera ${ }^{2}$, Patrick Kioko Mwanzia ${ }^{2}$, Ifeoma Malo ${ }^{1,3}$, \\ Yeside Dipo-Salami ${ }^{1,3}$ \\ 1 Power for All, San Francisco, CA 94108, USA \\ 2 Strathmore Energy Research Center, Strathmore University, Nairobi, 00200, \\ Kenya \\ 3 Clean Tech Hub Energy Innovation Center, Abuja, 900231, Nigeria \\ * Correspondence: Rebekah Shirley, Email: rshirley@strathmore.edu; \\ Tel.: +254-707-388-453.
}

\begin{abstract}
The future of work is a major source of uncertainty, especially in sub Saharan Africa (SSA), where climate change and artificial intelligence are changing the nature of agricultural employment, and where youth population is rising steadily. At the same time, SSA has the world's lowest rates of electricity access, presenting a barrier to economic productivity and gainful employment. According to the global tracking framework, decentralized renewable energy (DRE) technologies are fast becoming a popular vehicle for rapid delivery of electricity access, yet reports suggest the sector's expansion is hindered by a labor and skills gap. Thus, there is an opportunity for the growth of decentralized renewables to help tackle both universal energy access (SDG 7) alongside expansion of decent work opportunities (SDG 8). However, little data exists to date to support policy interventions. Our research explores the employment potential of the DRE sector by conducting the first comprehensive DRE sector jobs survey in SSA. We collect a year's worth of employment data from DRE companies in Kenya and Nigeria, two of the continent's most prominent DRE markets. We find that although nascent and just beginning to scale, the sector has already grown a formal workforce comparative to traditional utility-scale power sectors and has an informal workforce that may be twice as large. This article highlights our key findings on employment footprint, workforce trends and skills gaps, providing a baseline for further data collection.
\end{abstract}

\section{G Open Access}

Received: 29 July 2019

Accepted: 30 October 2019

Published: 19 November 2019

Copyright (c) 2019 by the author(s). Licensee Hapres, London, United Kingdom. This is an open access article distributed under the terms and conditions of Creative Commons Attribution $\underline{4.0 \text { International License. }}$
KEYWORDS: decentralized renewable energy; employment; productive power; gender; youth 


\section{INTRODUCTION}

\section{Motivation: Exploring Energy Access and Decent Work}

With the growing adoption of artificial intelligence and dramatic changes in global population demographics, the future of work is a source of major uncertainty, particularly in sub Saharan Africa (SSA). The growing impact of climate change on precipitation patterns, heat stress, water availability, and extreme weather severely impacts productivity in Africa's largely rain-fed agricultural sector, deepening its food crisis, and also affects the predictability and availability of work for millions in farming, which employs over $65 \%$ of the continent's labor force [1]. This is compounded by an increase in automation and mechanization, which reduces farm costs but jeopardizes traditional agricultural job opportunities. Meanwhile, as jobs grow scarce, recent improvements in healthcare access have led to a youth explosion, with many countries across SSA now having more than $20 \%$ of the total population between 15 and 24 years [2]. In fact, Africa's youth population is projected to double by 2050 to 840 million [3].

While a young population can be a major boon to the local economy and a positive force for growth, if the capacity to create new jobs is not cultivated in tandem with the population increase, it can lead to massive unemployment, increasing dependency on the existing working population, and persistent poverty. Employment data suggests that women and youth are most severely impacted by the dearth of employment opportunities, particularly those in rural communities [4]. Rural women, who make up the majority of agricultural and mining labor, are often unable to diversify away from these sectors even as employment opportunities decline, due to lack of education, traditional perceptions of gender roles, and a host of other sociocultural factors. Thus, the scale of the challenge is enormous, as the latest statistics make clear: young men and women between the ages of 15 to 24 comprise over $34 \%$ of the working-age population in SSA [5], and over 10 million jobless youth are looking for work every year [6]. See Table 1.

Amid this challenge, there is a major opportunity for economic development and employment creation through delivering energy access to 573 million people in SSA [7]. In 2017, national electricity access in SSA stood at $44 \%$ [8]. Rural electricity access, however, is even lower, at $22 \%$ [7]. Many SSA countries are in the midst of an energy transition as solar, wind, and electricity storage displace fossil fuel, and as rural electrification receives growing attention [9].

According to the World Bank [10], electrification strategies now generally comprise two main tracks: (i) grid electrification, or the expansion of national electricity grids, and (ii) off-grid electrification through community level mini-grid systems, or isolated devices and systems at the household level. These two approaches serve different population densities, have different capital requirements, and use 
different technologies. Grid electrification involves adding power plants and extending high-voltage transmission lines and distribution networks into unelectrified areas, leveraging advantages of existing physical infrastructure and systems for bill collection, economies of scale, and access to finance. In the past two decades more than 1.7 billion people have been added to national electricity networks worldwide, mostly in urban areas. Rural grid-electrification efforts, however, have been less successful, given the challenges of cost, remoteness, high line losses, low usage rates and revenue recoupment [7].

Alstone et al. identify persistent and pervasive "energy isolation barriers" which remote communities continue to experience with respect to centralized, grid-based electrification as a result of the multiple dimensions of geographic, economic and political remoteness [11]. As such, there has been greater emphasis in recent years on the role of off-grid electrification, through decentralized renewable energy (DRE) technologies, including solar lanterns, solar home systems (SHS), standalone and grid-tied commercial and industrial (C\&I) solar systems, solar water pumps and heaters, and mini-grids. As of 2017, at least 34 million people worldwide have gained Tier 1+ (i.e., $11 \mathrm{~W}$ and above) access through DRE technologies while about 120 million people have gained access to basic electricity lighting of less than $11 \mathrm{~W}$ [7]. According to the World Energy Outlook, 75\% of new electricity access will come through DRE solutions [12]. In fact, the World Bank projects that by 2030, 490 million people will be served by mini-grids, predominantly solarhybrid [13].

Despite an optimistic outlook for the expansion of DRE technologies, the sector faces many challenges. For instance, the DRE market is volatile and subject to multiple macro-economic risks. The pico-solar appliance market, for example, has grown at an average pace of 9\% between 2014 and 2016, but experienced a dramatic dip in sales in 2017 due to reasons like macroeconomic shocks particularly in India and Nigeria, extreme climate and droughts affecting farm community revenues and ability to pay in East Africa, and currency exchange risks in volatile economies [14]. Indeed, while DRE technologies can be less costly than grid expansion, they are often still too expensive for rural households to adopt, representing a customer affordability challenge without subsidy or financial support [15]. In 2016, Practical Action's survey of over 1800 rural households in Kenya found that $35-40 \%$ of the poorest households could not afford a SHS [16]. Furthermore, financial support for the sector remains marginal when compared to on-grid applications. While electricity finance reached an all-time high of US\$36 billion in 2017, more than US\$28 billion went into on-grid generation and US\$5.8 billion for transmission and distribution. Financing for off-grid and mini-grid applications in the same year received a disproportionate share of US $\$ 0.4$ billion [17]. Thus there are many challenges for scaling of the DRE sector, including access to a skilled workforce. Experts suggest that DRE 
technologies can create many direct jobs because of their growing market and inherently distributed nature. High level estimates from International Renewable Energy Agency (IRENA) suggest a potential of 4.5 million offgrid, renewable energy, direct jobs could be created globally by 2030 , which would account for more than one-sixth of the global renewable energy workforce, estimated to be 24 million by 2030 [18]. Yet according to a recent World Economic Forum report, human capital, which encompasses digital, technical, and vocational skills, is the area that is least prepared for the energy transition. In other words, universal energy access could also be an opportunity for direct job creation [19]. Importantly, in addition to direct jobs, there are clear signs that access to electricity is also creating productive use jobs within the communities gaining that access. Agriculture, the sector which still dominates the SSA economy, is likely best poised to benefit from the potential of clean energy access to mitigate climate change, unlock productivity, and thereby boost near-term economic growth and local job creation. Energy access (United Nations Sustainable Development Goal 7, also SDG 7), food security (SDG 2), and livelihoods (SDG 8) are inherently connected [20]. However, the impact of increased deployment of renewable technologies, and decentralized renewables in particular, has received little attention in the literature.

National decision makers and their donors in SSA and other energypoor regions have a unique opportunity to invest in the necessary resources to train the needed entrepreneurial, technical, financial, and managerial talent to deliver universal energy access while creating thousands of jobs. Otherwise, the lack of a skilled energy access workforce in emerging markets may hinder the achievement of government electrification targets, slow down the growth of more resilient energy infrastructure, and limit the potential of the energy sector to unlock major employment benefits. Yet very little data exists to support targeted policy for SSA. While some data does exist on job creation for utility scale renewable energy technologies in SSA, very few studies have explored the more nascent wave of decentralized technologies. There are few studies to date that provide an accurate job count for the DRE sector, and there is little quantitative data on the specific skills gaps that hinder sectoral growth. As such this paper contributes to the literature by specifically exploring the employment footprint of DRE technologies in SSA. 
Table 1. Key electrification and workforce metrics for Kenya and Nigeria.

\begin{tabular}{|c|c|c|}
\hline Key Electrification or Workforce Metric & Kenya & Nigeria \\
\hline National electrification goals & $100 \%$ by $2022[21]$ & $90 \%$ by $2030[22]$ \\
\hline 2018 official national electrification rate, including on- and off-grid connections & $75 \%[21]$ & $55 \%[23]$ \\
\hline 2017 Global Tracking Framework (GTF) national electrification rate [7] & $64 \%$ & $54 \%$ \\
\hline 2017 GTF national rural electrification rate [7] & $58 \%$ & $23 \%$ \\
\hline 2018 market penetration of solar lantern and SHS [14] & $51 \%$ & $4 \%$ \\
\hline $\begin{array}{l}2018 \text { labor force participation rate (persons actively engaged in or looking for work as } \\
\text { percentage of total working-age population) [5] }\end{array}$ & $66.3 \%$ & $55.2 \%$ \\
\hline $\begin{array}{l}2018 \text { women's labor force participation rate (women actively engaged in or looking for } \\
\text { work as percentage of total working-age women population) [5] }\end{array}$ & $63.6 \%$ & $50.6 \%$ \\
\hline $\begin{array}{l}2018 \text { youth labor force participation rate (youth actively engaged in or looking for work } \\
\text { as percentage of total working-age youth population) [5] }\end{array}$ & $35.7 \%$ & $23.2 \%$ \\
\hline $\begin{array}{l}2018 \text { unemployment rate (unemployed persons as percentage of total population actively } \\
\text { engaged in or looking for work) [5] }\end{array}$ & $9.3 \%$ & $6 \%$ \\
\hline $\begin{array}{l}2018 \text { youth unemployment rate (unemployed youth as percentage of total working-age } \\
\text { youth actively engaged in or looking for work) [5] }\end{array}$ & $18.5 \%$ & $19.7 \%$ \\
\hline $\begin{array}{l}2018 \text { women's unemployment rate (unemployed women as a percentage of total } \\
\text { working-age women actively engaged in or looking for work) [5] }\end{array}$ & $9.2 \%$ & $6.4 \%$ \\
\hline \multirow[t]{3}{*}{ Employment by sector in 2018 [5] } & Service: $35 \%$ & Service: $52 \%$ \\
\hline & Industry: $8 \%$ & Industry: $12 \%$ \\
\hline & Agriculture: 57\% & Agriculture: $36 \%$ \\
\hline
\end{tabular}

\section{Literature Review: Past Studies on DRE Employment}

To date there is little academic literature available on the relationship between energy access and job creation in SSA. One of the earliest attempts that explore renewable energy employment in SSA by Rutovitz et al. in 2009 projected that renewable energy could provide 453,000-755,000 jobs by 2030 in SSA, and a boost in domestic renewable technologies manufacturing capacity from $50 \%$ to $100 \%$ in 2030 could add an additional 86,000 jobs [24]. Later, in 2013, IRENA established an annual review series of renewable energy jobs, and found that while renewable energy has high job creation potential, employment created in SSA is very scarce [25]. In fact, in 2016, IRENA reported that of the 8.1 million renewable energy jobs created in 2015, only 45,000 were in SSA ( $0.6 \%)$, and 28,000 of those jobs were in South Africa [26]. The solar sector, however, has since boomed in the region, directly employing about 140,000 in 2018 [27]. In fact, Greenpeace now projects that under a 1.5-degree-celsius scenario, renewable energy (excluding biomass) could provide 4.5 million jobs in Africa by 2030 [28].

However, the employment potential of DRE technologies specifically is only now emerging as a discussion in the literature, especially given the recent international focus on addressing the challenges of rural 
electrification. DRE technologies are widely acknowledged as key to rural energy access, given their ease and speed of deployment, and their distributed nature. Early evidence in Bangladesh showed a linkage between job creation and SHS deployment [29], finding that the deployment of 1.2 million SHS for rural electrification created as many as 60,000 jobs [29]. In 2012, IRENA projected that 4 million jobs are needed to support DRE market potential by 2030 [18]. A later IRENA report revised the estimate to 4.5 million [25].

A majority of these studies, however, rely on recursive reference to a small set of employment factors applicable to limited geographical contexts. Cameron and Zwaan, in a study conducted in 2013, analyzed renewable energy employment factors from 70 publications, and found that only 31 yielded original results. Of the studies that were analyzed, none had a focus on SSA, except for two studies in South Africa. Thus, there is a clear need for improved data reporting and wider geographical spread of primary data on the employment impacts of renewables [30].

In 2014, Mills conducted one of the first studies on DRE jobs focused in SSA, exploring solar lanterns and their job displacement impact on kerosene lamps. Eight major companies disclosed employment information on their operations in Ethiopia, Haiti, India, Kenya, Malawi, Tanzania and Zambia, and their job displacement impact on kerosene lamps in Malawi and Kenya [28]. The results yielded that 38 jobs are created to serve 10,000 solar lantern users. Globally, 150,000 jobs were created to serve 44 million solar lanterns user [31].

Following Mills' study, Global Off-Grid Lighting Association (GOGLA) surveyed 40 off-grid solar companies, including those in the SHS sector. The study estimated that the off-grid solar sector can create 1.3 million jobs in East, West and Central Africa and South Asia by 2022, of which 567,000 are in SSA [32]. In a more recent job brief, GOGLA estimated that of the 1.3 million jobs, 510,000 are medium and high skilled, while 800,000 are low skilled [33]. With reference to mini-grids, the Energy and Environment Partnership Africa survey of its mini-grid portfolio in 2018 found that 36 direct jobs were created per mini-grid, though not specifying the breakdown between short- and long-term jobs [34].

The latest relevant study explores jobs projections for SSA from renewable energy and energy efficiency, finding that the share of renewable energy jobs comprise 37\% of energy sector jobs in 2020 given the current policies, and could comprise as much as 63\% in 2030 under aggressive climate policy [35]. This study only includes nuclear power, utility-scale solar PV, concentrated solar power and wind technologies, and does not include decentralized technologies.

Thus, few studies to date directly explore job creation for the comprehensive range of technologies serving off-grid and weak-grid areas or provide detail across employment categories. Our study adds to the literature by providing the largest and most comprehensive bottom-up 
employment data set for DRE technologies in SSA, allowing for nuanced insights on the workforce landscape and needs.

\section{METHODS}

\section{Research Scope and Data Collection Methods}

The goal of this exercise is to establish a baseline for understanding employment opportunities generated by the DRE sector. The survey was conducted in Kenya and Nigeria. Kenya's DRE market is one of the most mature in SSA and has the highest product penetration of solar lanterns and SHS in the world, with more than 50\% market penetration [14]. Nigeria has the largest potential DRE market in SSA, complete with the most ambitious mini-grid program, but conversely has a young DRE market, with very low, but rapidly expanding market penetration [14]. Exploring these two countries thus provide unique insights into the job and skill trends of DRE markets of different sizes and stages of growth, thus serving as an instructive starting point. The survey explores direct employment in the DRE sector, both formally and informally for these countries. We also discuss estimates of job creation stimulated through electricity access from DRE technologies, termed productive use jobs. Indirect and induced jobs are outside the survey scope. See Table 1 for a summary of each country's electrification and employment status.

The survey covers the breadth of DRE technologies, including small pico-solar products of less than $10 \mathrm{~W}$ that power a few bulbs and a phone charging station, SHS of roughly up to $200 \mathrm{~W}$ that power basic appliances such as TVs and refrigerators, standalone or grid-tied C\&I systems that range from a few hundred watts (W) to multiple kilowatts (kW), and minigrid systems that can be a few $\mathrm{kW}$ up to 10 megawatts (MW).

Off-grid productive use applications, such as solar irrigation, cooling and refrigeration, and agro-processing are gaining in popularity and have large projected potential market estimates [36], though actual commercial market penetration to date has been limited, except for solar water pumps. These technologies were in scope for the survey, and while we received a few responses from companies in the solar water pump sector, responses from other standalone, off-grid applications such as electric cooking, refrigeration and heating were extremely limited. Further, authoritative market estimates for these sectors are limited, making it difficult to scale results of the survey. We therefore only report on estimates of direct, formal jobs from solar water pumping in Kenya, where data is sufficient. Stronger outreach strategy for cooking, cooling and heating is planned for future studies.

The survey covered the local DRE value chain, including manufacturing and assembly (where applicable, such as in-house manufacturing or customization activity of a SHS company), import, wholesale, sales and distribution, project development and installation, operations and maintenance (O\&M), and ancillary DRE services such as finance, software, 
and technical support. The scope excludes out-of-country operations, such as manufacturing and assembly that take place primarily in countries like China and Germany. It also excludes end-of-life waste management, regardless of where it occurs.

For each country, we determined the local DRE market size by sales, installed capacity, geographical representation, and the total number of companies. Contact information was sourced for as many DRE companies as possible to create a comprehensive database for each country. The target sample size was then determined to ensure a statistically relevant representation of the total market. To achieve a confidence level of $90 \%$ and a confidence interval of $10 \%$, the target was 50 responses in each country. See total company and sample size estimates in Table 2. Over the course of three months, we contacted companies directly to complete the online survey, monitoring for representation across company types and geography.

Table 2. Survey sample size and statistics.

\begin{tabular}{lcc}
\hline Study Statistic & Kenya & Nigeria \\
\hline Estimated Total Companies & $150-200$ & $150-200$ \\
Desired Confidence Level & $90 \%$ & $90 \%$ \\
Desired Margin of Error & $10 \%$ & $10 \%$ \\
Required Sample Size & 51 & 51 \\
Total Survey Responses & 52 & 51 \\
Estimated Response Rate & $25 \%$ & $25 \%$ \\
\hline
\end{tabular}

${ }^{1}$ Estimated Total Companies is based on detailed contact lists of all companies known in the two countries compiled from multiple lists provided by in-country trade associations.

\section{Methods for Employment Estimate and Workforce Trends}

There are two types of studies used to determine employment impact for industries such as renewable energy: those that use "top-down" or "bottom-up" models. Top-down studies use input/output (I/O) models to model an entire economy as an interaction of goods and services between sectors and consumers, thus capturing shifts or displacements of jobs between sectors, and the induced trickle-down effect of spending on an economy known as “job multipliers". The top-down study provides useful insight into job impacts across different sectors of an economy, but in practice I/O models can be very complex, requiring current, highresolution macroeconomic data to isolate impacts of specific technologies or policies. Efforts to develop these I/O tables were limited for SSA countries except South Africa [37], and as such were not able to be employed in this study. Bottom-up studies rely on actual counts of direct and/or indirect jobs by technology type and the use of analytical methods to scale results. In bottom-up models the jobs per unit of end use product is normalized over the plant lifetime to determine a "job coefficient" which 
is then combined with market data to estimate job impacts at the level of the labor force. Bottom-up studies provide empirical estimates, but often do not provide granular insight into induced job multipliers or displacement. A full review of job estimation models can be found in $[35,38,39]$.

Our bottom-up study reports on the first-ever comprehensive job count for the DRE sector. In this study we estimate gross DRE employment in 2017-2018 at the country-level for direct formal, direct informal, and productive use jobs. With a single year's worth of jobs data normalization over technology lifetime is not possible. As such, we calculate an "employment factor" for each technology, as distinguished from a "job coefficient”. Multiplying employment factors from the survey data and market data from recent literature provide current job estimates and projections. The study is limited by data gaps. Most practitioners surveyed, for instance, reported little quantitative data on their customers' use of products for productive use activities. Estimates for productive use are thus taken from the literature. Likewise, due to limited data, indirect jobs are discussed only qualitatively by highlighting workforce trends in manufacturing and upstream supply chain companies and other DRE sectoral service companies. Finally, employment and the nature of jobs needed often change over time as companies and sectors mature. For this reason, several years of employment history is required to understand the potential future employment trajectory of a sector and determine job coefficients. Our t-test results do show a positive correlation between sales and employment by company, as well as age and company employment. Thus by using our survey's 2017 employment factors-with the caveat that these values will likely change in the future-and the latest market estimates publicly available for each technology type in each country, we provide at least a basic extrapolation of potential gross future DRE sector employment. See Table 3 for definitions of each type of job as defined in this study. A fuller description of assumptions and study limitations follows, and all data used for projections is found in the supplemental material.

Using survey data, we also break down workforce trends by job function, gender and youth participation, retention, and level of compensation. We conducted statistical analyses, including $t$-test, ANOVA and linear regression to determine the statistically significant relationships for each country's sample. These analyses provide a highresolution view into the composition of the DRE workforce and shed light on needed skills. See supplementary materials for these outputs.

Lastly, to help contextualize findings of the quantitative survey data, qualitative focus groups were also held in Kenya and Nigeria in December 2018. The convened focus groups comprised industry leaders, financiers, training institutes, and policymakers to validate findings and to provide expert opinion on the trends and skills challenges the data highlights. The focus groups discussed issues such as gender balance, youth engagement, 
technical and vocational education and training (TVET), productive use jobs, which also allow for a more nuanced interpretation of data findings. A total of 14 experts in Kenya and 17 in Nigeria participated and provided expert opinion. Our survey implementation, focus group moderation, data analysis, and interpretation was conducted in partnership with local research institutions and sector experts in each country.

This study thus provides an initial baseline and early estimate of DRE employment based on one year of company survey data and the available literature. Beyond the scope of this study, socioeconomic and macroeconomic exploration of local labor markets are required to fully understand potential job displacement, as well as induced, indirect, informal, and productive use jobs. Findings from this study should not be generalized. A thorough discussion of the study limitations is found in the Discussion. See the supplementary material for full analytical methods.

Table 3. Employment terms and definitions.

\section{Employment terms Definitions}

Employment factor An employment factor measures the number of jobs created per unit of produced product or service. For instance, direct employment factors are calculated based on the number of total direct, formal jobs and number of products sold or systems built, in sales unit or capacity terms.

Full-time employment

A full-time employee is on the payroll with a registered company, enjoys benefit as an employee, and works full-time hours, which is generally more than 35 hours per week, but may differ according to company policy.

Part-time

employment

A part-time employee is on the payroll with a registered company but does not work full-time hours, which is defined according to company policy.

Full-time equivalent An FTE job is the equivalent of one employee working full time over the course of a year where (FTE) job full-time work is defined in accordance with the country context. Part-time and contract work are converted to FTE based on number of hours worked or length of contract. All estimates of direct, formal jobs are presented in FTE job terms. All other references to jobs outside of direct, formal employment do not assume full-time equivalency.

Direct, formal jobs In the scope of this study, direct, formal jobs are those created through contractual engagement with an incorporated company in the DRE sector. For example, an IT professional or a project manager who is employed by a DRE company.

Indirect jobs Indirect jobs are those created by backward-linked industries or companies that serve and supply the DRE sector. That is, those vendors and suppliers who serve the DRE sector upstream or provide services for the DRE sector's day-to-day operations either contractually or noncontractually. For example, indirect jobs are those created by an inverter manufacturer or an importer who supplies DRE companies. Literature on indirect jobs is cited where available. 
Table 3. Cont.

\section{Employment terms Definitions}

Informal sector

Direct, informal jobs

Induced jobs

Productive use jobs

Retention

Senior managers

Skilled workers
According to the International Labor Organization (ILO), the informal sector comprises all work for unincorporated enterprises and for which no complete accounts are available that would permit a financial separation of the production activities of the enterprise from other activities of its owner(s). Informal jobs can even be extended to include non-remunerative work of contributing family members, and thus can be difficult to bound definitively [40].

Those informal jobs that are created through contractual or non-contractual engagement with an incorporated company in the DRE sector. Informal employment in the sector takes on various forms-from long-term arrangements with companies (e.g., product retail) to commission-based sales activities. For example, a home business owner who works as a village sales representative for a SHS company [40].

Induced jobs are those created through forward linkages as workers in the DRE sector spend salaries on goods and services throughout the larger economy. For example, during the construction of a mini-grid plant, induced jobs are created for food vendors and water fetchers at the construction site. Induced jobs are estimated using "job multipliers". However, this study does not explore the macroeconomic effects of spending on the economy and further job creation thereof. Induced jobs are excluded from the analysis and this report [25].

Productive use jobs are those created by the DRE end users themselves as a result of newlyacquired or enhanced electricity access. For the purpose of this study, productive use is defined as any income-generating application of a DRE product or service [41]. For example, the new jobs created by the purchase of a solar milling plant. Productive use jobs are estimated through insights from focus groups and literature, as most surveyed respondents did not readily have data on jobs created by their product or service offers at the customer level.

Retention is the total period of time that an employee continues to work with an organization [42].

For the purpose of this study, senior managers include the top executive management of a company, such as the CEO, CFO, and COO.

Skilled workers are those who hold leadership, management, professional, technical, or associate professional positions. Their responsibilities typically involve the performance of complex technical and practical tasks that require an extensive body of factual, technical, and procedural knowledge in a specialized field, as defined by the International Standard Classification of Occupation (ISCO-08) Skill Level [43]. Workers in Skill Level 3 or above are considered skilled workers. While there is a qualification and skills framework developed by the East African Community, there is little substantial difference between these frameworks [44]. Our study adopts the ILO framework to allow for consistency and comparability with results from other SSA countries.

Youth are defined as persons between the ages of 15 to 24 [45]. 


\section{Practitioner Groupings and Description of Sample Set}

A total of 103 organizations completed the survey: 52 in Kenya and 51 in Nigeria (see Table 2). This jobs sample is the largest and most comprehensive coverage of DRE technologies known at the time of publication. Nevertheless, results should not be generalized to other countries or regions. From the survey responses, we find that most companies work across different types of DRE technologies and are engaged in multiple parts of the value chain, particularly pico-solar appliance and SHS companies. This makes it difficult to squarely account for jobs according to one technology type such as SHS, because many SHS companies are also engaged in selling pico-solar appliances or activity involving other technologies. Further, employment cannot easily be strictly associated with specific segments of the value chain because a majority of companies work across various parts of the value chain. For instance, some SHS companies work more in product distribution while others are also heavily engaged in project development and installation. Likewise, employees tend to cover a broad spectrum of functions even within a single company.

As such, survey respondents are broadly categorized into five practitioner groupings according to their business model and the market segments they serve based on their predominantly advertised market service or product offering. There is overlap between some of these groupings and while this does not greatly affect total employment estimates, results cannot be generalized. The practitioner groupings are defined as follows:

1. End-user product providers, which sell pico-solar appliances, SHS, solar water pumps, and/or other DRE products to end users. This group of companies get their main revenue from product sales, and interface directly with DRE end users.

2. Project developers and installers, whose revenue mainly comes from the development and implementation of projects instead of products. They develop and install C\&I systems. They are usually involved in procurement of PV panels and batteries, site feasibility study, system design and development, construction, and installation. Note that the term project development here should not be interpreted as "predevelopment," which is legal work, regulatory work, project design, and site development.

3. Mini-grid operators, which are private companies that operate and maintain mini-grid systems and are characterized by sales of electricity as an integrated part of their business model. Many mini-grid operators also design, develop and install projects. Companies which develop and construct mini-grids, but do not operate them, are considered project developers and installers. 
4. Manufacturing and upstream supply chain companies, or those whose core business is in manufacturing, assembling, importing, and wholesale.

5. Sector service providers, who work closely with DRE companies to deliver services such as microfinancing for energy access, metering and software services, training, human resources, research, and advocacy.

In the survey sample, companies are fairly represented across the different company types, though in both countries more responses were received from project developers and installers. More specifically, among the 52 respondents in Kenya, 14 were end-user product providers, 28 were project developers and installers, 3 were strictly mini-grid operators, 3 were manufacturing and upstream supply chain companies, and 4 were sector providers. In our Nigeria sample of 51 companies, 9 were end-user product providers, 24 were project developers and installers, 7 were minigrid operators, 6 were manufacturing and upstream supply chain companies, and 5 were sector service providers. During focus group discussion, we confirmed with experts that the samples were reflective of the market.

Among the 103 survey respondents, there are outlier companies which employ significantly more workers than other companies, especially in Kenya. We describe the impact of these large employers, and where possible, we also describe the differences between local and foreign companies. While a large number of survey respondents from Kenya were foreign companies, only a few were in Nigeria. Finally, while we attempted to capture the sector's local, indirect job footprint, only few manufacturing and upstream supply chain companies and sector service providers responded to the survey. As such, we cannot accurately estimate or project indirect jobs at the national level. We report on the sample's findings for these two groupings where possible.

\section{Market Estimates and Key Assumptions}

The direct formal, direct informal and productive use employment estimates are based on employment factors from the survey and market estimates from the literature. Kenya and Nigeria together account for 10\% of global off-grid market potential, and the larger East Africa and West Africa markets together attracts $63 \%$ of global investments in the off-grid solar sector [14]. Here we describe key market estimates used for scaling job impacts.

For the smaller pico-solar appliances and the SHS market, GOGLA reports this market to be mature in Kenya, with a penetration rate of more than $50 \%$, though still nascent in Nigeria. This is largely due to the strong mobile money ecosystems in Eastern Africa, providing easier entry for pay-as-you-go sales. In terms of current sales performance, 916,000 and 216,000 pico-solar appliances and SHS were sold in Kenya and Nigeria respectively in 2017 [46,47]. 
The outlook for the two pico-appliance and SHS markets are also very different. Kenya, a more mature market with a significant existing customer base, will see a growth in demand for SHS as customers upgrade to higher-tier use of electricity. Nigeria, on the other hand, is expecting a faster pace of growth, due to its recent favorable policy for off-grid solar [14]. Such trend can already be observed over the last few years. Between 2014 and 2016, the Kenya off-grid solar sector had an average annual sales growth rate of $11 \%$ while Nigeria averaged $35 \%$ [14]. There is also less competition in Nigeria currently, as compared to Kenya, where there are more than 20 major companies already in the market, so growth is anticipated to be very fast in Nigeria, as has already been observed over the past years [14].

Current and future market estimates for C\&I and mini-grid systems are much less certain. Currently, there are likely around 65 mini-grid systems in Kenya and 30 in Nigeria, and about 15 MW and 10 MW of newly-added C\&I system capacity in 2017 for Kenya and Nigeria respectively [48-50]. Though the mini-grid market is still becoming established, it has high job creation potential as it continues to receive support from governments and multi-lateral development partners. In Kenya, for instance, the World Bank funded the expansion of 147 mini-grids in low-access counties to be completed by 2024 [51]; while the Nigeria Electrification Project, also World Bank funded, aims to provide electricity to 30,000 households and 30,000 micro-, small- and medium enterprises (MSMEs), through solarhybrid mini-grids [52].

Overall, the global mini-grid market is expected to power half a billion people by 2030 [13]. Yet, despite the international support that mini-grids receive, the sector continues to face a number of challenges, including high costs, low consumers ability to pay, the rapid expansion of grid, etc. As such, many experts predict mini-grid growth will be much slower than policy and programs suggest, lending great uncertainty to market estimates.

Finally, standalone off-grid applications such as irrigation, and productive use applications, such as cooling and refrigeration and agroprocessing have tremendous market potential in SSA. The solar water pump market alone is US\$456 million in SSA and has potential to reach US $\$ 1.63$ billion by 2030 [36,53,54]. Efficiency for Access reported 3000 pumps sold in East Africa and 2000 for the rest of SSA, in the second half of 2018 for GOGLA member companies. However specific country sales are generally not available. In Kenya, it is estimated that the solar water pump sector has installed about 10,000 pumps, though future projections are not available. Authoritative country level estimates of the current or projected market size for Nigeria were not available however, and as such only job estimates for Kenya are reported. Table 4 summarizes the market estimates and forecasts used in the analysis. Details can be found in the supplementary materials. 
Table 4. DRE market estimates and forecasts for 2017-2018 and 2022-2023.

\begin{tabular}{|c|c|c|c|c|}
\hline \multirow[b]{2}{*}{ Market Estimate and Forecast } & \multicolumn{2}{|r|}{ Kenya } & \multicolumn{2}{|c|}{ Nigeria } \\
\hline & 2017-2018 & 2022-2023 & 2017-2018 & 2022-2023 \\
\hline $\begin{array}{l}\text { Pico-solar appliances and SHS } \\
\text { market estimate and forecast }\end{array}$ & $\begin{array}{l}\text { 915,643 products } \\
\text { sold }[46,47]\end{array}$ & $\begin{array}{l}1,490,000 \text { products sold }(1,100,000 \\
\text { private sector-driven sales and } 390,000 \\
\text { public sector-driven sales) }[14,21,46,47]\end{array}$ & $\begin{array}{l}215,575 \text { products } \\
\text { sold }[46,47]\end{array}$ & $\begin{array}{c}108 \text { MW sold } \\
\text { [55] }\end{array}$ \\
\hline C\&I market estimate and forecast & 15 MW [55] & $\mathrm{N} / \mathrm{A}$ & 20 MW [55] & $\mathrm{N} / \mathrm{A}$ \\
\hline $\begin{array}{l}\text { Mini-grid market estimate and } \\
\text { forecast }\end{array}$ & $\begin{array}{l}65 \text { systems in } \\
\text { operation [49] }\end{array}$ & 135,000 connections $[21]$ & $\begin{array}{l}30 \text { systems in } \\
\text { operation [50] }\end{array}$ & $\begin{array}{l}405 \mathrm{MW} \text { total } \\
\text { capacity [55] }\end{array}$ \\
\hline $\begin{array}{l}\text { Solar water pump market } \\
\text { estimate and forecast }\end{array}$ & 10,000 pumps sold & $\mathrm{N} / \mathrm{A}$ & $\mathrm{N} / \mathrm{A}$ & N/A \\
\hline
\end{tabular}

\section{RESULTS}

\section{Employment Footprint}

This study found that the DRE sector has a major impact across the direct formal and informal job markets. In 2017-2018, the DRE sector accounted for 10,000 direct, formal FTE jobs in Kenya, and 4000 in Nigeria. The DRE sector also relies heavily on informal work, employing almost twice as many people in the informal sector: 15,000 informal jobs in Kenya, and 9000 in Nigeria (see Table 5). As mentioned earlier, an informal job does not necessarily equate full-time engagement. In both countries there is a positive linear relationship between both direct, formal and informal jobs, and units of product sales. Meaning that companies which have higher sales employ more across both the formal and informal sector. Also, ANOVA analysis shows that a relationship between company scope and employment. Those companies that work broadly across delivering multiple technologies employ more persons than those engaged in a single DRE technology. Finally, we find that direct, formal jobs show a positive relationship with the age of the companies, particularly for Nigeria. The older a company is, the more direct, formal jobs it provides. See supplementary materials for these statistical outputs and for market estimates used. In the sections below, we expand on these findings and their implications. 
Table 5. Direct, formal and informal jobs estimates, by technology, in 2017-2018.

\begin{tabular}{lcccc}
\hline & \multicolumn{2}{c}{ Kenya } & \multicolumn{2}{c}{ Nigeria } \\
\cline { 2 - 5 } DRE Technologies & $\begin{array}{c}\text { Direct, } \\
\text { formal jobs }\end{array}$ & $\begin{array}{c}\text { Direct, } \\
\text { informal jobs }\end{array}$ & $\begin{array}{c}\text { Direct, } \\
\text { formal jobs }\end{array}$ & $\begin{array}{c}\text { Direct, } \\
\text { informal jobs }\end{array}$ \\
\hline Pico-solar and SHS & 7500 & 15,000 & 1100 & 8400 \\
Standalone and grid-tie C\&I & 1800 & 200 & 2700 & 390 \\
Solar water pumps & 95 & N/A & N/A & N/A \\
Mini-grid & 260 & 290 & 120 & 9 \\
TOTAL & 10,000 & 15,000 & 4000 & 9000 \\
\hline
\end{tabular}

\section{Direct, Formal Jobs}

In 2017-2018, the DRE sector provided 10,000 direct, formal jobs in Kenya and 4000 jobs in Nigeria (see Table 5). This is equivalent to the total number of jobs within the traditional power sector in Kenya, and the electricity, gas, steam, and air conditioning sector in Nigeria [56-58]. In Kenya, total national formal employment in 2018 was about 18 million [5]. Kenya Power and Lighting Company (KPLC) had about 11,000 personnel in 2018 [57]. So the DRE sector, having provided 10,000 jobs in 2017-2018, is already comparable to the jobs created by the distribution and retail segment of the utility-scale power sector. The Kenyan DRE sector was dominated by pico-solar appliance and SHS companies. In fact, 78\% of formal Kenyan jobs were in the pico-solar appliances and SHS sector, followed by another $18 \%$ in the C\&I sector, and $4 \%$ from mini-grids and solar water pumps.

In Nigeria, a total of 55.5 million people were employed in 2017 [5], among which the electricity, gas, steam, and air conditioning supply sector employs about 10,000 people [58], thus putting the DRE sector employment on the same order of magnitude as the utility-scale power sector. This is despite the fact that the DRE market is still nascent in Nigeria, despite a large and unmet appetite for power lead by Nigeria's MSMEs. This is due, in part, to the country's current economic crisis and high import duties on batteries [6,59]. In Nigeria, project developers and installers are the primary job engines for the DRE sector. The DRE market in Nigeria is dominated by C\&I projects that serve urban, peri-urban, and rural consumers from grid-tied backup solar systems or standalone electricity supplies. The survey estimates that in 2017-2018, the Nigeria DRE sector provided 4000 jobs directly, with $71 \%$ of the direct DRE jobs provided by the C\&I sector, followed by $26 \%$ in the pico-solar appliances and SHS sector, and $3 \%$ by the mini-grid sector.

Our estimates group align with the latest regional estimates, though these are few. GOGLA, for instance, estimates that the pico-solar appliance 
and SHS sector has provided about 77,000 FTE jobs along the value chain in East Africa in 2018, and 26,000 in West Africa [32]. Following GOGLA's study, IRENA reported that PV jobs in Africa, including on-grid and off-grid applications, employ about 140,000 in 2019 [27]. Greenpeace also estimated that total PV jobs in Africa is about 66,000 in 2015 and projected to be 108,000 by 2020 [28].

\section{Direct, Informal Jobs}

The informal sector is an important driver for emerging economies like Kenya and Nigeria. Often the major source of employment, in Kenya, $82.7 \%$ of the employed population are informal workers, similar to $92.9 \%$ in Nigeria [60,61]. Likewise, in the DRE sector, direct, formal employment is just the tip of the iceberg: there are a large number of informal jobs such as field technicians and commissioned sales agents. According to the survey findings, the DRE sector relies heavily on informal work, employing almost twice as many people informally as it does formally. In 2017-2018 the sector was responsible for 15,000 informal jobs in Kenya, and 9000 in Nigeria (see Figure 2). A majority of this informal work is attributed to end-user product providers such as pico-solar appliance and SHS companies, which depend on a wide network of distributors, retailers, and technicians to serve their customers. Thus, Nigerian DRE companies employ fewer informal workers compared to Kenya. In Nigeria, there is high demand for DRE products in both on-grid and off-grid areas because of the poor quality of the national grid [62]. Perhaps, since much of the distribution of DRE products takes place in urban areas, less extensive informal networks are necessary. Further exploration into local, informal supply chains is warranted.

Informal jobs, though greater in number than direct, formal jobs, may involve several different arrangements, from long-term agreements with DRE companies as product retailers, to commissioned sales activities. Focus groups indicated that informal workers often work with several companies and have multiple income streams, so level of engagement, quality of labor, and level of compensation may vary. Informal workers generally do not have secure employment contracts, benefits, social protection, or representation. Generally, informal workers are retained for shorter periods than regular, full-time employees, as shown below. An explanation for the differences in retention time was not captured through the survey, and warrants further analysis as informal sales can range from independent agents to family members of all ages. It is therefore difficult to compare compensation or retention between informal workers and their formal counterparts, or to calculate informal employment as FTE jobs based on survey data. Deeper research into DRE employment characteristics within the informal sector is warranted. 


\section{WORKFORCE TRENDS}

\section{Retention and Level of Engagement}

We define the level of engagement for direct, formal employees based on whether they work full-time, part-time, or as contractors. The level of engagement is high across both countries, as the vast majority of direct, formal jobs created by the DRE sector are full-time. In Kenya $68 \%$ of the jobs are full-time, with $65 \%$ in Nigeria. Furthermore, according to the survey, the average retention time for direct, formal, full-time DRE employees is more than 30 months for both countries. This suggests the DRE sector may create more stable jobs than larger scale renewables. For instance, one-time construction jobs account for $81 \%$ of wind power project jobs in India [63].

Table 6. Workers' retention and level of engagement.

\begin{tabular}{lcc}
\hline Engagement Metric & Kenya & Nigeria \\
\hline Formal, full-time retention & 33 months & 36 months \\
Informal job retention & 10 months & 12 months \\
Level of engagement & Full-time 68\% & Full-time 65\% \\
& Part-time 10\% & Part-time 10\% \\
& Contract 22\% & Contract 16\% \\
\hline
\end{tabular}

The survey also shows the level of engagement and retention across each company type (see Table 6). DRE end-user product providers and mini-grid operators provide more full-time employment than other company types. These two company types are not only employing the most full-time staff, but among employees, their retention time is also the highest. On average, their employees stay with companies for more than three years, as compared to two years for project developers and installers, manufacturing and upstream supply chain companies, and other service providers. Thus, among its direct, formal employees the DRE sector provides long-term jobs.

\section{Levels of Compensation}

Differences in wage compensation across the DRE sector can be explored across different stakeholder groups. For instance, alongside observing the differences in monetary compensation across gender, we can also observe wage differences between formal and informal workers, or managerial and nonmanagerial employees. Note that not all respondents provided complete information on compensation: $65 \%$ of respondents from Kenya, and 70\% of respondents from Nigeria reported wages, reducing the confidence level for this particular question to $80 \%$ with a $10 \%$ margin of error. Thus, findings on compensation from the sample cannot be generalized. Other limitations are found in Section "Limitations of the Study". 
In terms of level of compensation, wages for direct, formal employment from the DRE sector largely fall within the middle-income range for their respective countries, positioning the sector as a strong employment opportunity for job seekers (see Table 7). Furthermore, compared to the average gender wage gap of $14.6 \%$ in low-income countries [64], the DRE sector may have greater parity in its compensation policies.

Table 7. Managerial, nonmanagerial and informal worker earnings.

\begin{tabular}{lcc}
\hline Wage Metric & Kenya & Nigeria \\
\hline Male managerial employee monthly wage & US $\$ 2100$ & US $\$ 1400$ \\
Female managerial employee monthly wage & US $\$ 2000$ & US $\$ 1400$ \\
Male nonmanagerial employee monthly wage & US $\$ 1100$ & US $\$ 710$ \\
Female nonmanagerial employee monthly wage & US $\$ 1000$ & US $\$ 700$ \\
Male informal worker monthly wage & US $\$ 280$ & US $\$ 66$ \\
Female informal worker monthly wage & US $\$ 270$ & US $\$ 80$ \\
\hline
\end{tabular}

In Kenya, DRE employees earn, on average, wages that fall within the middle-income range as defined by the Africa Research Institute, earning between US $\$ 764$ and US\$1204 per month [2]. The main wage differentiator seems to be the presence of foreign capital. There is a stark wage difference between employees of local companies and foreign companies operating locally. Managers working for foreign companies earn more than three times the average salary of managers working for local companies. Similarly, nonmanagerial employees in foreign companies earn more than double their counterparts. This trend does not seem to follow in Nigeria, where there was more reported wage parity across the foreign and local company responses. However, more comprehensive data on the employment behavior of local and foreign companies would be needed to draw definitive conclusions.

Wages earned by DRE employees in Nigeria generally fall in the range of a middle-class income, or US\$480-645 [42]. The survey shows that across most DRE company types, nonmanagerial employees have an average wage in this range, except for mini-grid companies, whose employees earn US\$900 per month. Conversely, service provision company's nonmanagerial employees earn, on average, less than US\$300 per month. In Nigeria, wages among men and women in the DRE sector appear to be on par with one another, a deviation from the national trend. In a recent report by AfDB, Nigerian non-youth women's median wage was found to be $45 \%$ lower than the median wage of non-youth men [65].

In terms of monthly earnings, the survey data does not provide a full picture of an informal worker's total monthly income across various income streams.

\section{Job Types and Job Function Breakdown}

Survey data found that the majority of jobs in the DRE sector are skilled jobs. Skilled jobs are defined by the ILO as those involving leadership, 
management, professional, technical or associate professional skills generally at the International Standard Classification of Occupations (ISCO) Skill Level 3 or above [43], which is the equivalent of East Africa Community Qualification Framework's Level 5 or above [44]. In Kenya, $66 \%$ of the DRE jobs are skilled, compared to $70 \%$ in Nigeria. By comparison, the global utility-scale solar sector's workforce is less than $50 \%$ skilled [66]. This may point to another potential benefit of employment in the DRE sector: the opportunity for skilled workforce engagement.

The type of skills being recruited in each country and sector is different. For instance, in Kenya more than a third of the DRE workforce is engaged in sales and distribution, given the mature pico-solar appliance and SHS market. On the other hand, the Nigeria workforce has only $8 \%$ of its direct, formal employees dedicated to sales and distribution. This could be due to the nascency of the market in Nigeria [14], or possibly due to the fact that the market is not distinctly segmented between rural and urban customers given the low quality of the national grid [62]. Rather, the dominant skills currently demanded in Nigeria are project development, installation, and O\&M. Management and business administration account for more than $15 \%$ of skills required by companies in each country, again demonstrating the need for skilled labor. Figure 1 below shows the job function breakdown of the DRE sector in 2017-2018 for Kenya and Nigeria. The findings can be validated by the African Development Bank's recent report on the continents' job trends. It highlighted that while technology innovation in automation and artificial intelligence may not wipe out many middle- and low-skilled jobs, as the continent is not dependent on manufacturing, the need for skilled and creative workers is imminent [65].

These findings are similar to other skill estimates for the energy sector. Greenpeace, in its energy transition study in 2019 broke down the energy workforce according to the ISCO framework, with managers (ISCO 1) and other professional finance and legal support (ISCO 2) accounting for 19\% of the workforce in 2015 in Africa, engineers (ISCO 2) and technicians (ISCO 3) 25\%, and plant or machine operator (ISCO 8) and laborer (ISCO 9) $22 \%$. While the Greenpeace result roughly corresponds to our findings, it appears the DRE sector is more dependent on a large sales workforce, especially where the pico-solar appliance and SHS market is more mature. As will be discussed in a later section, the transferability of most skills between DRE and the utility-scale sector makes competition for talents a challenge for retaining employees. 


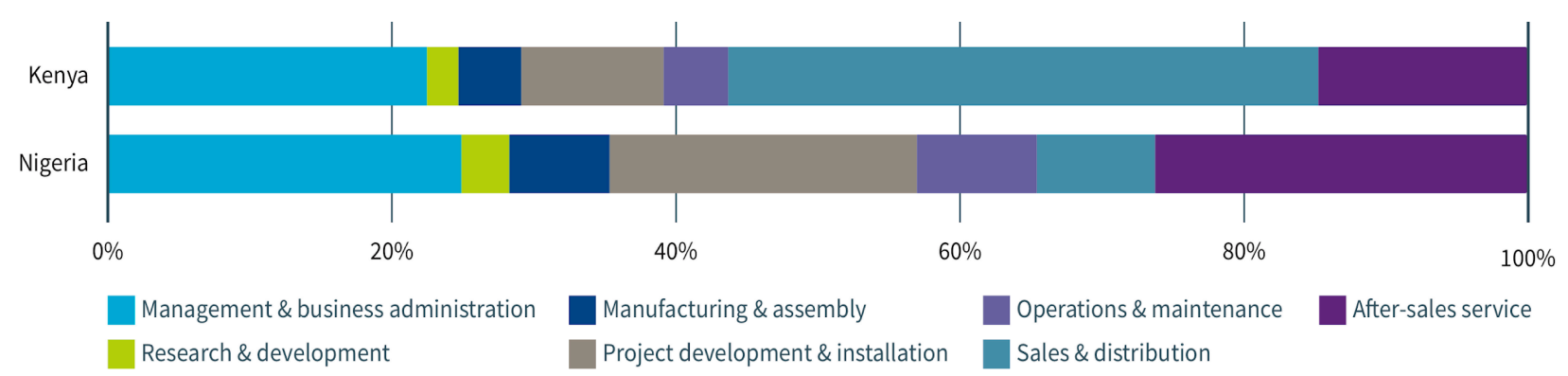

Figure 1. Direct, formal job function breakdown in 2017-2018.

\section{Youth and Women's Participation}

Youth and women's participation in the workforce are critical for emerging economies. Across SSA, there are high rates of working poverty, vulnerable employment and underemployment for youth, and even more so for rural youth or those with little education [65]. Likewise, across SSA women are more likely than men to be unemployed [5]. In addition to high unemployment rates, women and youth, when employed, are disproportionately engaged in the informal sector with less security. About $75 \%$ of employed women do so through informal employment, as compared to $61 \%$ for men; about $80 \%$ of employed youth are in the informal sector, as compared to $66 \%$ for the total working-age population [65].

The survey found that women's participation in the DRE sector is low for both countries (see Table 8). Women make up less than $30 \%$ of the workforce: $23 \%$ in Kenya and $27 \%$ in Nigeria. This is lower than women's participation in the renewable energy industry in general-IRENA reported in 2019 that women represented an average of 32\% of the global renewable energy workforce [67], and in 2017 found that gender discrimination in renewable energy is less pronounced than in the energy sector at large [56].

The survey data showed that women represented $25 \%$ of the senior managerial positions in Kenya in 2018, and 26\% in Nigeria (see Table 8). It is difficult to compare the DRE sector to others due to limited data, however, focus groups highlighted that structural barriers do exist for women seeking to occupy leadership positions due to discriminatory social norms and gender stereotypes. For instance, during the Nigeria focus group, it was reported that DRE companies led by women were intentionally excluded from contract tenders because the sector lacks trust in female leadership. Deeper stakeholder analysis is merited to identify practical solutions.

Corresponding to the general workforce trends in SSA, there is a higher representation of women in informal employments in the DRE sector, and particularly with pico-solar appliance and SHS companies. The benefit of engaging women in the sales and distribution network is widely recognized by both SHS and mini-grid companies alike, and is validated by the literature, which shows that in rural communities women play 
important roles as entrepreneurs, social networkers, influencers, and leaders, making them suitable salespersons. For instance, during focus group discussion Solar Sister confirmed that its female sales agents performed better than their male peers. In 2017, Baruah reported the important role DRE technologies play in generating employment opportunity for women but warned that transformative shifts in societal attitudes about gender roles are necessary [68].

Scaling the DRE sector may represent a major opportunity to help unemployed youth. The survey found that in Kenya the percentage of youth employed in the DRE sector is high, at more than $40 \%$ of the workforce. However, in Nigeria, which is a very young population, youth currently only make up $28 \%$ of the DRE workforce. ANOVA analysis shows that statistically, local companies employ more youth than foreign companies. See supplemental materials for these outputs.

Table 8. Women and youth participation in DRE workforce.

\begin{tabular}{lcc}
\hline Participation Metric & Kenya & Nigeria \\
\hline Percentage of women employees & $23 \%$ & $27 \%$ \\
Percentage of managers that are women & $25 \%$ & $26 \%$ \\
Percentage of women informal workers & $35 \%$ & $42 \%$ \\
Percentage of youth employees & $41 \%$ & $28 \%$ \\
\hline
\end{tabular}

\section{Workforce Profiles}

Despite the broader employment impact numbers, there are important nuances that can be understood by disaggregating jobs according to company type. For instance, some company types offer longer-term jobs than others, require different skill sets, and have different levels of participation among women and youth. In this section we build a workforce profile for each company type to highlight key characteristics (see Figures 2 through 7).

End-user product providers, including pico-solar appliances and SHS, have a low market penetration rate in Nigeria 4\% in 2017, and a much higher penetration of $51 \%$ in Kenya. That said, in both countries, the workforce profile is similar (see Figures 2 and 3). A large share of direct, formal jobs created by these companies are skilled activities, like sales and distribution or product servicing, as compared to the global renewable energy industry, where less than half of its workers are skilled [25]. These companies have high percentage full-time engagement, high retention periods, and a broad spread of job functions from business and administration to assembly and sales. ANOVA analysis shows that enduser product providers employ more women than other companies. 


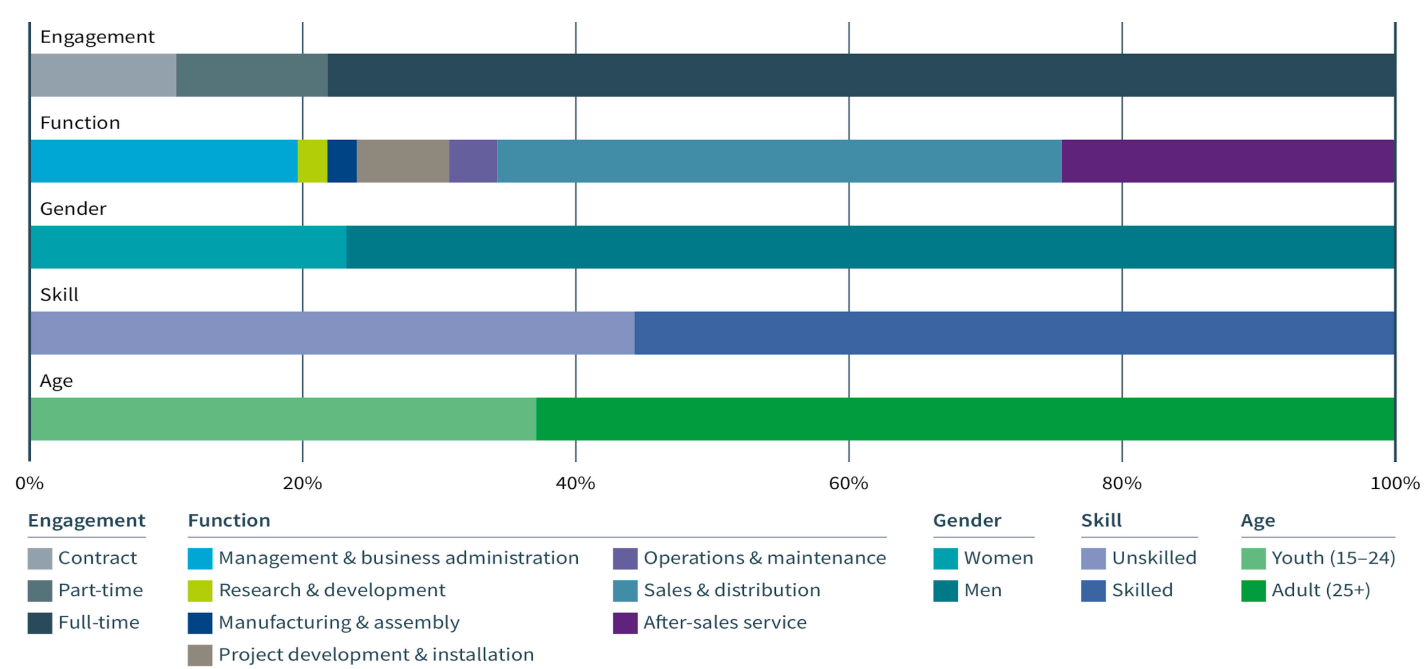

Figure 2. Kenya end-user product provider workforce profile.

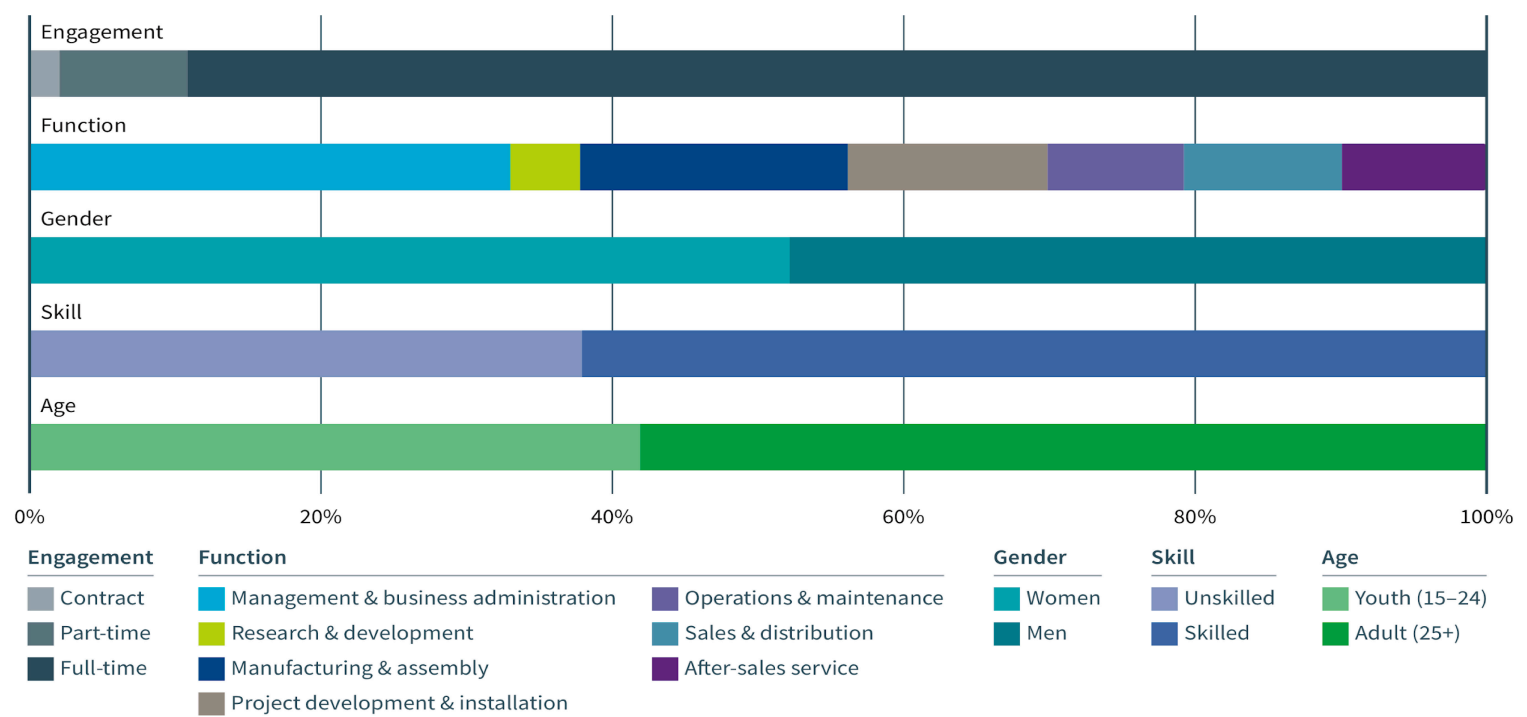

Figure 3. Nigeria end-user product provider workforce profile.

Project developers and installers on the other hand draw less on sales and distribution, and dedicate most of their workforce to project development and servicing products, which are highly skilled jobs (see Figures 4 and 5). Because of the less standardized, component-based nature of project development and installation, the work carried out is labor intensive. Furthermore, during the construction phase of C\&I projects, the developers and installers draw heavily on support of engineering, procurement, construction, transportation, and logistics companies, with the support of local civil workers. Thus, the potential for indirect job creation is high. These jobs also have high retention and a significant degree of full-time engagement. The project developer workforce in Kenya comprises over $40 \%$ youth, though with a lower notably lower participation in Nigeria. However, ANOVA analysis shows that project developers and installers employ less women than other company types. 


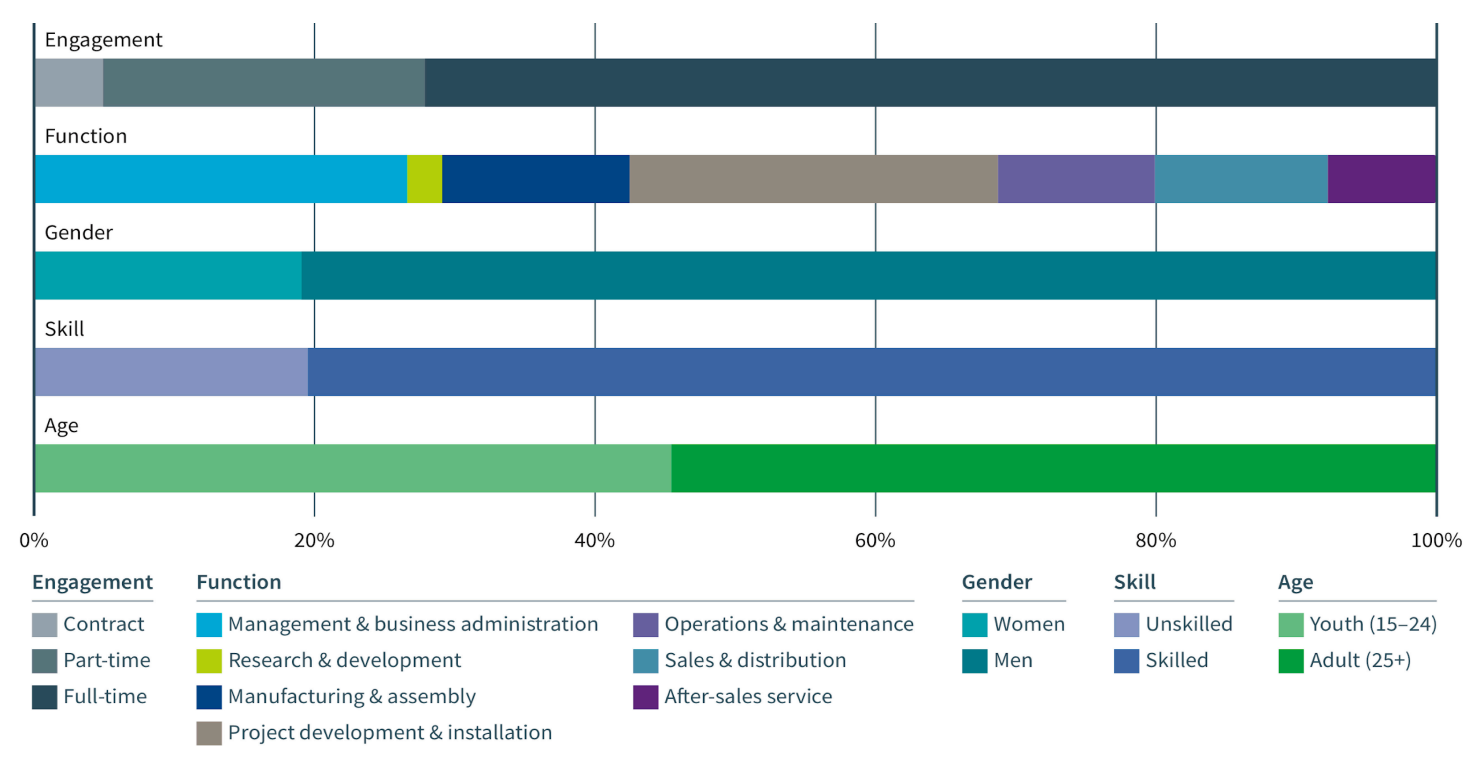

Figure 4. Kenya project developer and installer workforce profile.

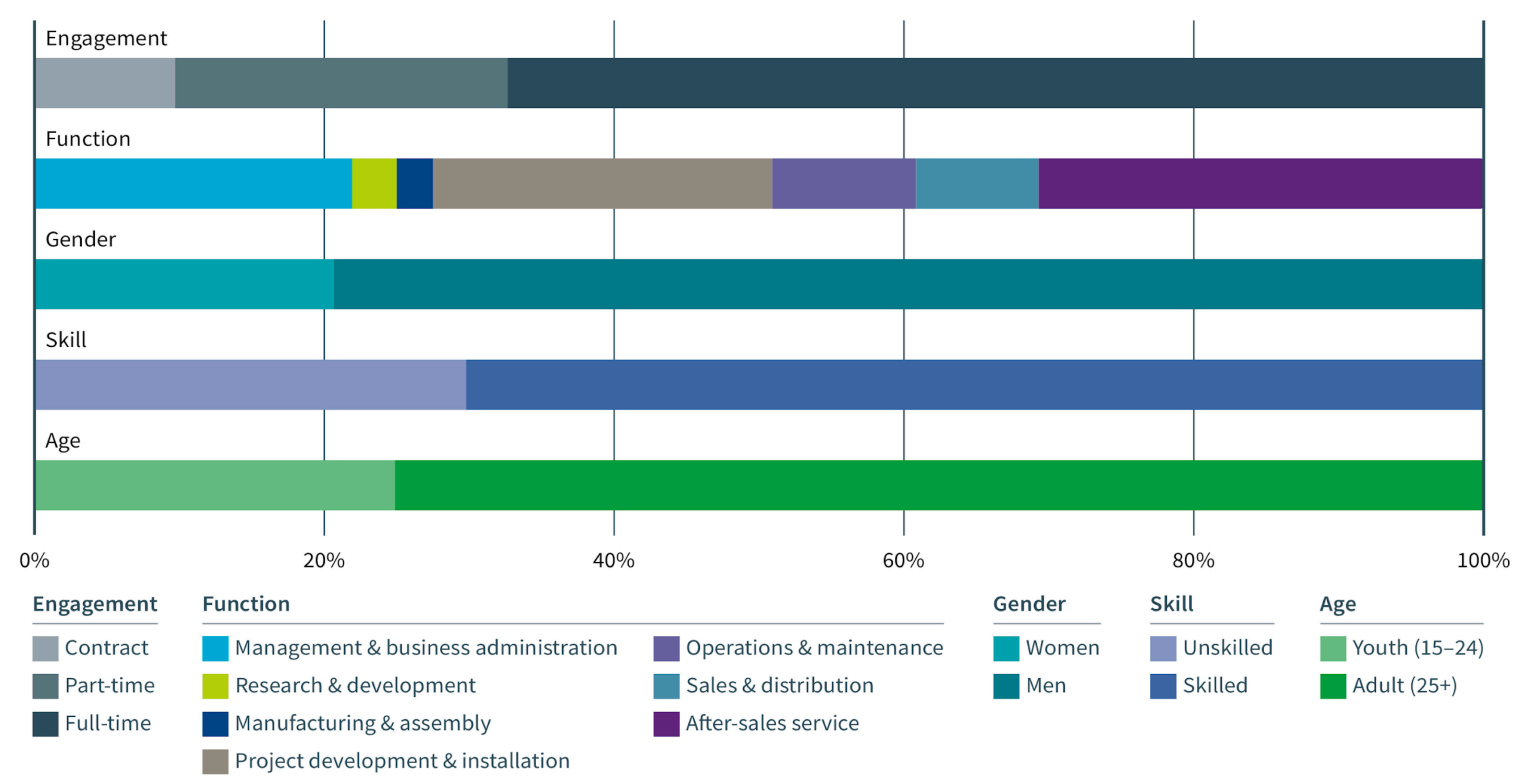

Figure 5. Nigeria project developer and installer workforce profile.

Mini-grid operators and project developers and installers are analyzed separately because their business models and revenue structures differ, as does their contracting and hiring behavior. Mini-grid operators create more long-term O\&M jobs, as compared to project developers and installers, who need large number of contractors or informal workers' support over a short period of time during project installation. Currently, mini-grid companies are still emerging in Nigeria and more established in Kenya. Mini-grid companies for instance, provide significantly more formal than informal work opportunities. The jobs created by the minigrid operators are mostly full-time, long-term jobs, in fact having the longest retention time across the company types surveyed. Furthermore, mini-grid companies employ the highest percentage of their staff in management and business administration (see Figures 6 and 7). 


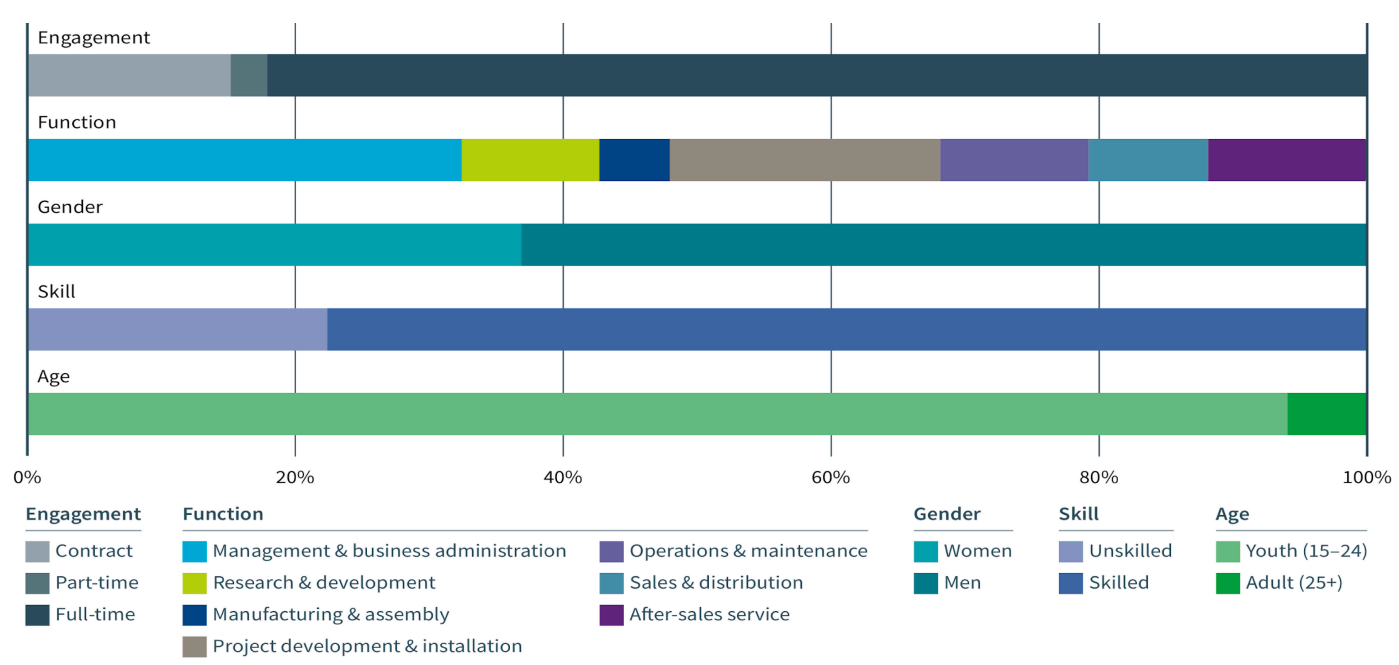

Figure 6. Kenya mini-grid operator workforce profile.

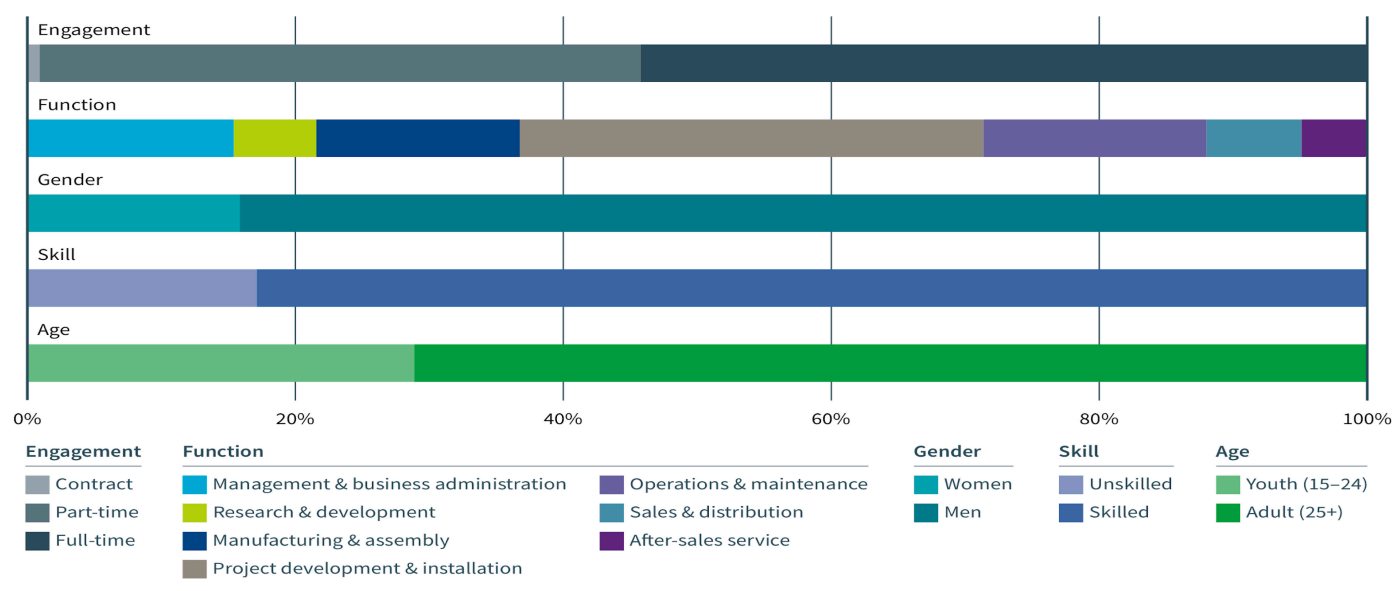

Figure 7. Nigeria mini-grid operator workforce profile.

As our response numbers for manufacturing, upstream supply and service providers were low we do not produce workforce profiles for these indirect company types.

\section{Recruitment Challenges and Training Needs}

The characterizations above help unearth the nature of employment in the DRE sector and its potential to provide highly skilled, diverse, and wellpaid jobs. However, local workforce readiness is crucial to unlock this potential and is thus also crucial to achieving universal energy access. The survey results and our focus groups suggest that DRE companies struggle to recruit the necessary talent, and that strategic policy on training youth and easing recruitment challenge could support a stronger DRE workforce. In this section we explore recruitment challenges and key skills gaps of the sector.

Firstly, according to the survey, it is more difficult to recruit youth and women than older men. The main challenge that DRE companies face when recruiting women is a limited talent pool. In all country focus groups, it was noted that the lack of women's participation in the DRE sector was 
related to the more general lack of female representation in science, technology, engineering and mathematics (STEM) education, which itself stems from broader, complex sociocultural challenges. There is also gender bias in recruitment, which is well documented in the literature [69]. Moreover, representatives from training institutes in both Kenya and Nigeria explained that often, even when women are directly targeted during recruitment, the number of applications received is still low.

Furthermore, from the survey responses, youth employment in the DRE sector is less than $50 \%$ in both countries. Companies surveyed in Nigeria said lower youth engagement resulted from a limited talent pool, lack of experience, and poor work ethic, noting that it is more difficult to find qualified youth than older candidates. In Kenya, youth had higher salary expectations and face the challenge of a lack of established recruitment channels for youth. These findings shed light on the necessity of creating more accessible training and education avenues for young people and the need for more established recruitment pipelines to bring youth into the DRE workforce.

Interestingly, the survey findings also point to a demand that is often overlooked in the DRE sector: the need for more business and innovation talent. In both countries, business administration jobs, such as management, business development, and finance, make up $20 \%$ of the DRE workforce. Though not one of the largest job categories, according to all focus groups, managerial expertise is the most difficult skill set to recruit. Most companies agreed that technical training is a secondary consideration, since staff can be trained internally if needed. The primary challenge is recruiting employees with a strong grounding in business skills, ethics, and workplace leadership. This corresponds to recent findings of the Mini-Grid Training Needs Assessment, a report jointly prepared by Energy 4 Impact and INENSUS, which identified project and business management, finance, health and safety, monitoring and evaluation, O\&M processes, and software as core skills that lack adequate training programs in emerging markets [70]. The challenges around recruiting and retaining managerial talent is compounded by competition for the limited talent pool. Further, as noted in the focus groups, managers from DRE companies tend to move to the utility-scale or rooftop solar sectors, which have more managerial positions and thus more upward mobility.

The survey and focus groups show that a strong TVET and career strategy which involves government, industry, education institutions, and investors is needed to close the skills gap for the sector. Information feedback loops between TVET systems and employers are important to avoiding the mismatch between young workforce entrants' skillsets and employers' needs [65]. Past successes have been observed in many private sector-led training programs. During focus group discussions, participants shared success cases of industry working directly with universities to establish a presence and develop a pipeline that recruits students during 
their formal education into industry through internships and on-the-job training that quickly leads to full-time employment.

For most DRE companies, technical talent is recruited from across many training institutes with different curricula, teaching standards, and levels of accreditation. Indeed, participants in both focus groups expressed concern over the quality of training, the lack of monitoring and evaluation metrics for such training programs, and the inability to transfer accreditation across countries or regions, both complicating and limiting the recruitment process. Thus, there is a need for better certification processes and, perhaps, for a collective industry-wide training curriculum. Another identified gap in recruitment is industry knowledge of available training services. Many companies are not aware of the training resources available for their staff or even where to source trained technicians. These insights have important implications for workforce development policy and the tailoring of interventions to the DRE sector's needs. We explore the implications of these findings in the Discussion.

\section{Employment Projections and Productive Use}

This data shows that the DRE sector, though very nascent, does support direct employment in SSA. Skilled labor will be needed to scale the sector, and thus even greater employment opportunity may arise in the nearterm future, especially given that $23 \%$ of emerging economies with low energy access have now established official DRE targets [71]. We attempt a projection of future DRE workforce by applying the study employment factors to available market forecasts and planned policies (see Table 9). This simple exercise suggests that by 2022-2023 employment from the DRE sector could more than double. The DRE sector could provide more than 17,000 and 52,000 direct, formal jobs in Kenya and Nigeria respectively. The DRE sector could also provide more than 30,000 in direct, informal jobs in Kenya, and 24,000 in Nigeria. This snapshot provides a general indication of employment potential but cannot be generalized given the data and analysis limitations. See supplementary materials for market assumptions used.

Moreover, future employment from productive use jobs is likely to be even greater than that of direct employment. Though included in the survey instrument, data from DRE companies on the types of jobs being created by rural customers through access to electricity was poor. As such, we were unable to generate productive use employment factors, or project productive use employment in the future. But as an anecdotal point of reference, if we explore the few employment factors available in the literature, productive use jobs stimulated by access to electricity may employ more than five times as many people as direct, formal jobs. In fact, the scale of productive use job impact in 2017-2018 is estimated at 65,000 jobs in Kenya and 15,000 in Nigeria (see Table 9 and see Supplementary Materials for more information on employment factors and market estimates used). This basic calculation aligns with expert opinion from the 
focus groups and the literature, which suggest that the number of jobs created through access to electricity from DRE may be orders of magnitude larger than the direct employment of the sector itself [72-74]. Among the different DRE productive use applications, solar water pumping for irrigation has a particularly high employment impact documented in the literature. According to the Food and Agriculture Organization (FAO), solar irrigation can increase the number of harvests and area of crop coverage, therefore requiring more labor [53,75]. Due to limited data however, we could not estimate the productive use jobs from solar water pumping. Future exploration into productive use employment and skills needs is critical, especially as rural unemployment is such a timely challenge in SSA.

Table 9. Key national employment estimates for 2017-2018 and 2022-2023 projections.

\begin{tabular}{|c|c|c|}
\hline Job Estimates & Kenya & Nigeria \\
\hline Direct formal jobs estimate in $2017-2018$ & 10,000 & 4000 \\
\hline Direct informal jobs estimate in $2017-2018$ & 15,000 & 9000 \\
\hline Productive use jobs estimate in $2017-2018$ & 65,000 & 15,000 \\
\hline Direct formal jobs projection in $2022-2023$ & 17,000 & 52,000 \\
\hline Informal jobs projection in 2022-2023 & 30,000 & 24,000 \\
\hline $\begin{array}{l}\text { Percentage change in direct, formal jobs } \\
\text { between } 2017-2018 \text { and } 2022-2023\end{array}$ & Increased by $70 \%$ & Increased by $1200 \%$ \\
\hline $\begin{array}{l}\text { Percentage of women in direct, formal DRE } \\
\text { workforce 2017-2018 }\end{array}$ & $23 \%$ & $27 \%$ \\
\hline $\begin{array}{l}\text { Percentage of youth in direct, formal DRE } \\
\text { workforce 2017-2018 }\end{array}$ & $41 \%$ & $28 \%$ \\
\hline $\begin{array}{l}\text { Top } 3 \text { skills in } 2017-2018 \text { (percentage of } \\
\text { DRE direct, formal workforce positions) }\end{array}$ & $\begin{array}{l}\text { (1) Sales and distribution ( } 41 \%) \\
\text { (2) Management and business } \\
\text { administration (22\%) } \\
\text { (3) After-sales service (15\%) }\end{array}$ & $\begin{array}{l}\text { (1) After-sales service (26\%) } \\
\text { (2) Management and business } \\
\text { administration (25\%) } \\
\text { (3) Project development and installation } \\
(22 \%)\end{array}$ \\
\hline $\begin{array}{l}\text { Key assumptions for productive use job } \\
\text { estimate in } 2017-2018\end{array}$ & $\begin{array}{l}\text { Based on employment factors shared } \\
\text { by experts and market estimates } \\
\text { from literature. }\end{array}$ & $\begin{array}{l}\text { Based on employment factors shared by } \\
\text { experts and market estimates from } \\
\text { literature. }\end{array}$ \\
\hline $\begin{array}{l}\text { Key assumptions for } 2022-2023 \text { job } \\
\text { projections }\end{array}$ & $\begin{array}{l}\text { Based on specific KNES objectives. } \\
\text { These estimates show the } \\
\text { incremental employment impact of } \\
\text { individual public-sector DRE } \\
\text { initiatives. }\end{array}$ & $\begin{array}{l}\text { Based on SEforALL's } 2030 \text { action agenda. } \\
\text { This projection may be high as the country } \\
\text { is already falling short of its DRE } \\
\text { deployment plan designed by SEforALL. }\end{array}$ \\
\hline
\end{tabular}




\section{DISCUSSION}

\section{Key Insights}

In this section we explore key insights from the survey data, focus groups, and literature. This is the first study to explore direct employment from the DRE sector in SSA. These initial findings suggest that while the DRE sector is nascent and just beginning to scale, it has already grown a workforce equivalent to the traditional utility-scale power sector. Importantly, the survey shows this to be largely skilled, full-time and longterm employment. Furthermore, early indicators suggest that as markets grow, significant pools of skilled labor will be required.

Pico-solar appliance and SHS companies currently drive employment in the DRE sector, though employment from mini-grids may grow, given the ambitious mini-grid targets that many SSA countries have set. Because of this, sales and distribution skills account for the largest share of jobs, and are important for sustaining the DRE sector, while management skills represent a critical gap for unlocking further growth. Importantly, while management and business positions only compose a fifth of the sector's direct, formal jobs, across all countries surveyed this is reported as the most critical and difficult skill set to recruit, hampering the sector's expansion. Alongside this, DRE companies reported that general business soft skills are critically lacking, affecting every aspect of company performance. These soft skills include leadership, finance, strategic planning, communication, chains of command, project management, compliance, anti-harassment, and health and safety.

Women's participation in the direct, formal DRE workforce is low. On average, women make up about a quarter of the DRE workforce, less than the broader global renewable energy sector where women account for $32 \%$ of employees. Women are even less represented in direct, formal managerial positions. Women's participation increases in the informal sector, where they make up more than half of the sector's informal workforce, due to the recognized importance of women's influence in rural sales and distribution networks. Youth participation was higher, though DRE companies agree that there are more opportunities for women and youth if recruitment and training challenges can be overcome.

Finally, the survey findings suggest that in addition to direct, formal employment, the DRE sector may employ twice as many workers through informal jobs and five times as many through productive use jobs-though these are difficult job sectors to accurately assess. This is critical as informal work is the largest source of employment for SSA. Not only is the scale of informal and productive use jobs important, but also the fact that they are predominantly rural in nature, given the geography of DRE markets. As new micro-enterprise opportunities and agricultural value chains are explored, the impact could grow significantly. Thus in SSA where agriculture is still the main source of livelihood, DRE technologies 
may simultaneously presents a solution to energy access and rural unemployment, warranting further investigation of this intersection.

\section{Recommendations}

The above insights lead to a series of recommendations for the sector and its stakeholders. For instance, there are clear skills needed to scale the DRE sector acknowledged as critical to delivering universal energy access. Filling these skills gaps would create more employment and present an opportunity for collaboration between government, academia, training organizations, and industry associations. Such partnership is required to develop standardized, accredited, industry-relevant curricula and for the establishment of career development programs for graduates. Opportunities for industry exposure, such as apprenticeships, practicum exercises, and short-term internships, are an important component of an excellent curriculum.

Furthermore, since the sector presents an important rural employment opportunity, it is key to develop training programs easily accessible by rural communities. Especially given the growing importance of productive use to the DRE business model, companies also pointed to the need for basic micro-enterprise training among rural end users, from book-keeping to business planning. Further study of value chains is necessary to identify market opportunities and the interventions necessary to establish these businesses.

Soft skills training may be an opportunity for shared training services as this particular skills gap was noticed across the sector, and most DRE companies do not have the resources or bandwidth for internal training. More than two-thirds of DRE companies reported that they work across multiple parts of the value chain, so developing tailored, short, soft skills and rural micro-enterprise training programs for the entire DRE sector through collaboration with local higher education and TVET institutions could support the DRE companies themselves while also encouraging a well-rounded, qualified workforce. Shared technical training resources would be more difficult to achieve as companies often have proprietary technology that cannot be shared publicly, or which would make standardization of the curricula difficult.

Stronger youth engagement could be an important solution to the growing challenge of unemployed youth in many emerging economies. The lack of experience and pipelines for youth recruitment present a challenge. As noted, stronger industry collaboration with higher education and TVET institutions is needed to create well-functioning and highly visible recruitment channels, such as university clubs, open days, and job tours for graduates, are also important to help young people navigate the gap from campus to employment. Establishing updated, accessible, regional databases of certified technicians is another simple solution to provide companies with easier access to vetted, qualified skilled labor and recent graduates. Gender equality should also be considered in the early 
design stage of these programs to increase uptake of employment opportunities among women.

Similarly, there is opportunity for greater participation of women in the sector. Low participation is related to many broader sociocultural challenges around gender stereotypes, recruitment biases, discriminatory business cultures, and women's representation in STEM education. Encouraging women's participation in the labor force is important, as unemployment rates are higher among women, especially rural women. At the same time, women are beneficial to the DRE sector in particular areas of the value chain. Identifying other such areas where women provide direct value to companies is important, but engaging women in the DRE sector should begin with developing and implementing gender equality policies and practices across the sector, such as gender equality selection criteria for grants and tenders, as well as directly encouraging greater participation of women in the types of education and training programs mentioned earlier. Stakeholders directly engaged in women's empowerment should be part of the policy development process.

Finally, the sector's massive footprint in the informal sector presents an opportunity to encourage the formalization of labor to align with local and international decent work standards, compensation standards, and social protections. Not only do informal workers have less stability and lower wages, but they are often more exposed to macroeconomic risks. For example, sales agents are strongly affected by even short-term, seasonal fluctuations in electricity demand. Helping to secure and formalize the livelihoods of informal workers would allow the sector to better support local economies. This is particularly important as women account for a majority of informal jobs. Industry associations can play a key role in aligning the sector around such standards. Developing pathways to certify skilled, but uncertified, technicians is one way to help formalize rural employment opportunities, but there are many other ways the DRE sector itself, government, and investors, can collaborate around formalization of the workforce.

\section{Limitations of the Study}

Finally, we address key study limitations that impact the analysis.

Sample representation: This survey sample is the largest dataset on DRE jobs in emerging markets known at the time of publication. Nevertheless, there are several large DRE companies that, together, have a majority share of reported sales in the sample and therefore affect the employment factor strongly and its ability to be applied across the sector for national estimations. In these cases, we sought the opinion of industry experts on the market share of these big companies. In cases where the sample did not reflect the average market situation, outliers were removed from the study. As the survey is replicated over time the sample size should improve, thereby improving the statistical significance of the results. 
Consideration of the role of private and foreign investments: This iteration of the survey does not consider the role of investment on growth. Depending on international trends in investment, certain technologies may grow more quickly, or may have better paying jobs. On the other hand, if sufficient private financing is not leveraged, ambitious expansion targets will not be achieved. Thus, both current and future employment estimates depend heavily on investment and finance.

The availability of high-quality market estimate and forecast data: To scale survey results to the national level, the study applies employment factors derived from the survey data to future market estimates. Some DRE technologies, such as the solar water pump market in Kenya and Nigeria, lack market data and therefore their future employment footprint cannot be properly measured. Furthermore, future market estimates differ between governments and the private sector, when they exist. The most recent and best available estimates are used where possible.

Employment patterns over time: Given this is the first survey performed for the sector, it is not able to provide comparative insight into how employment behavior changes over a DRE company's trajectory. For instance, as companies grow to scale it is possible that less labor will be required per unit produced. These patterns greatly affect employment factors over time, impacting the accuracy of future employment estimates. Though the survey asked about company age, this provides little insight as there is only a single year's worth of data to observe. A key reason to replicate this study is to understand employment patterns over time.

Consideration of job displacement: Given the lack of available data, the study does not explore past, current, or future job displacement that may result from fuel switching or automation. The net employment impact of the DRE sector across direct, indirect, and productive use job categories will be significantly influenced by displacements elsewhere in the economy. This is a major limitation to understanding the scale of net employment. Broader macroeconomic studies are required.

Comparability of direct, formal, direct, informal, and productive use jobs: Informa and productive use jobs are difficult to job aggregate. Due to lack of data about the nature and time involved in work, direct, informal and productive use jobs are not readily translated into FTE terms and therefore cannot be compared in scale to direct, formal jobs. Further study is required.

Wages and compensation: Many companies chose not to answer survey questions on wage, or only reported male wages. In addition, the survey was directed towards DRE company leadership or human resource employees whose response to compensation policy may be more conservative. Employee oriented surveys and deeper analysis are required for stronger conclusions.

Comparability of wages between direct, formal and direct, informal employment: In the survey, companies reported the earnings received by informal workers for an average month of engagement with their 
company. This does not provide a full picture of an informal worker's total monthly income across various income streams. It also is not informed by the number of hours or days that an informal worker is engaged with said company. It is therefore difficult to compare levels of compensation between formal and informal workers according to survey data.

Indirect job estimates: Due to the limited number of upstream and sector service providers that responded to the survey, and the limited quantitative data in the literature, indirect jobs cannot be readily estimated. It is also difficult to attribute employment in these sectors directly to DRE companies. Further research into in-country and external supply chains is required.

Induced job estimates: Induced jobs are not included in the study scope. Future iterations of the study may leverage ongoing work from other research organizations building macroeconomic analysis tools for our target countries.

Productive use job estimates: Companies responding to the survey had very little confidence in productive use job estimates from their products or services. Standard measurement and evaluation frameworks are required for the sector. Productive use job estimates for SHS and minigrids are derived from the literature and expert opinion solicited in focus groups. These estimates are thus incomplete, may be biased toward early adopter behavior, and do not considering productive use jobs from C\&I, solar water pumping, or other DRE technologies. Furthermore, productive use employment factors from the literature are often anecdotal or based on limited study not involving randomized controls. This study's estimates for productive use jobs have limited statistical significance and warrant further study.

\section{CONCLUSIONS}

Delivering energy access to millions of people and businesses worldwide through DRE technologies will require employing substantial numbers of people. This study is the first of its kind, offering a bottom-up job survey for the DRE sector in two key SSA markets. Early estimates show that while the potential for direct jobs is large, the potential for informal and productive use jobs may be far larger. However, more consistent and standardized data collection is needed by the sector.

The current size of the DRE workforce is already comparable to the utility-scale energy sector in Kenya, and the electricity, gas, and steam sector in Nigeria. As the DRE sector expands the workforce may grow larger. The DRE sector is thus a potential solution to two of the biggest challenges in emerging economies: access to clean energy (SDG 7) and job creation (SDG 8). Given that the DRE sector creates long-term, skilled, middle-income jobs, it is strategic policy to invest resources to solve training and recruitment challenges, to strengthen the DRE workforce.

Future work will involve reiterating the survey in Kenya and Nigeria as well as expanding to other SSA countries to gather insight into their 
patterns of hiring and employment, allowing us to better understand future market growth and job creation. We also intend to implement a broader set of survey tools that will allow more extensive research into productive use jobs. Additionally, we aim to explore indirect jobs from upstream sectors and job displacement from traditional energy sectors. Such analysis will provide better insight into the job creation potential and workforce needs of specific value chain segments, including manufacturing and service sectors. Finally, we aim to conduct a more comprehensive analysis of youth and women's participation in the energy access workforce.

\section{SUPPLEMENTARY MATERIALS}

The following supplementary materials are available online at https://doi.org/10.20900/jsr20200001.

\section{DATA AVAILABILITY}

All data generated from the study are available in the supplementary materials.

\section{AUTHOR CONTRIBUTIONS}

RS and C-JL designed the study and survey tool. RS led the study exercise and wrote the paper with input from all authors. C-JL coordinated data collection and led on data analysis and visualization. HN, SO and PM led data collection in Kenya, coordinated the local focus group, and contributed to data interpretation and writing the paper. IM and YD-S led data collection in Nigeria, coordinated the focus group, contributed to data interpretation and review of paper.

\section{CONFLICTS OF INTEREST}

The authors declare that there is no conflict of interest.

\section{FUNDING}

This research was kindly funded by the Schneider Electric Foundation and the Rockefeller Foundation. Funding was acquired by Power for All.

\section{ACKNOWLEDGEMENTS}

The authors wish to thank William Brent, Director of Communications, Power for All for editing support and constructive comments on paper style. The authors wish to thank all survey respondents for their data input, and all colleagues from NGOs, energy companies and research institutions that reviewed the work and provided feedback.

\section{REFERENCES}

1. Fact Sheet: The World Bank and Agriculture in Africa. The World Bank. Available from: http://go.worldbank.org/GUJ8RVMRL0. Accessed 2019 Jun 3. 
2. How Kenya is failing to create decent jobs. London (UK): Africa Research Institute; 2017.

3. Africa's population explosion is a ticking time bomb-African Development Bank Governors. Abidjan (Côte d'Ivoire): African Development Bank; 2018. Available from: https://www.afdb.org/en/news-and-events/africas-populationexplosion-is-a-ticking-time-bomb-african-development-bank-governors-17900/. Accessed 2019 May 1.

4. Mind The Gap: The State of Employment in India. New Delhi (India): Oxfam India; 2019.

5. Data Finder-World Employment and Social Outlook. International Labour Organization. Available from: https://www.ilo.org/wesodata/. Accessed 2019 Jun 3.

6. Ighobor K. Africa's jobless youth cast a shadow over economic growth. Africa Renewal. Special Edition on Youth. New York (US): United Nations; 2017.

7. 2019 Tracking SDG 7: The Energy Progress Report. International Bank for Reconstruction and Development. Washington, D.C. (US): The World Bank; 2019.

8. Access to electricity (\% of Population). The World Bank. Available from: http://data.worldbank.org/indicator/EG.ELC.ACCS.ZS. Accessed 2017 Jan 25.

9. Decentralized Renewables: From Promise to Progress. San Francisco (US): Power for All; 2017.

10. State of Electricity Access Report 2017. Washington, D.C. (US): The World Bank; 2017.

11. Alstone P, Gershenson D, Kammen DM. Decentralized energy systems for clean electricity access. Nature Clim Change. 2015;5(4):305-14.

12. World Energy Outlook 2018. Paris (France): International Energy Agency; 2018.

13. Mini Grids for Half a Billion People: Market Outlook and Handbook for Decision Makers. Washington, D.C. (US): The World Bank; 2019.

14. Off-Grid Solar Market Trends Report 2018. Washington, D.C. (US): GOGLA, Lighting Global, ESMAP, Dalberg Advisors; 2018.

15. Neidl C. Can the Microfinance Sector Help Deliver Clean Energy? Washington, D.C. (US): CGAP; 14 May 2012. Available from: http://www.cgap.org/blog/canmicrofinance-sector-help-deliver-clean-energy. Accessed 2017 Jan 25.

16. Poor people's energy outlook 2016: National energy planning from the bottom up. Rugby (UK): Practical Action Publishing; 2016.

17. Energizing Finance: Understanding the Landscape. Vienna (Austria): Sustainable Energy for All; 2019.

18. Renewable Energy Jobs and Access. Abu Dhabi (United Arab Emirates): International Renewable Energy Agency; 2012.

19. Fostering Effective Energy Transition: A Fact-Based Framework to Support Decision-Making. Cologny (Switzerland): World Economic Forum; 2018.

20. Connolly-Boutin L, Smit B. Climate change, food security, and livelihoods in sub-Saharan Africa. Region Environ Change. 2016;16(2):385-99.

21. Kenya National Electrification Strategy: Key Highlights. Nairobi (Kenya): Kenya Ministry of Energy; 2018. 
22. Rural Electrification Strategy and Implementation Plan. Abuja (Nigeria): Federal Government of Nigeria; 2016.

23. Nigeria Electrification Project Appraisal Report (PESR/PERN/RDNG). Abidjan (Côte d'Ivoire): African Development Bank; 2018.

24. Atherton A, Rutovitz J. Energy Sector Jobs to 2030: A Global Analysis. Sydney (Australia): Institute for Sustainable Futures, UTS; 2009.

25. Ferroukhi R, Lucas H, Renner M, Lehr U, Breitschopf B, Lallement D, et al. Renewable Energy and Jobs. Abu Dhabi (United Arab Emirates): International Renewable Energy Agency; 2013.

26. Ferroukhi R, Khalid A, Renner M, López-Peña Á. Renewable Energy and Jobs-Annual Review 2016. Abu Dhabi (United Arab Emirates): International Renewable Energy Agency; 2016.

27. Renewable Energy and Jobs-Annual Review 2019. Abu Dhabi (United Arab Emirates): IRENA; 2019.

28. Teske S, Dominish E, Briggs C, Mey F, Rutovitz J. Outlook on employment effects of a global energy transition. Amsterdam (Netherlands): Greenpeace; 2019.

29. Bimesdoerfer K, Kantz C, Siegel JR. Killing Two Birds with One Stone: Driving Green Jobs through Creating a Rural Renewable Energy Systems Industry. Presented at the UNRISD Conference on Green Economy and Sustainable Development: Bringing Back the Social Dimension, 2011 Oct 10-11; Geneva, Switzerland.

30. Cameron L, Zwaan B. Employment factors for wind and solar energy technologies: A literature review. Renew Sustain Energy Rev. 2015;45:160-72.

31. Mills E. Job creation and energy savings through a transition to modern offgrid lighting. Energy Sustain Dev. 2016;33:155-66.

32. Employment opportunities in an evolving market. Off-grid solar: creating high-value employment in key markets. Utrecht (Netherlands): GOGLA; 2018.

33. Energizing job creation: employment opportunities along the off-grid solar value chain. Utrecht (Netherlands): GOGLA; 2019.

34. Opportunities and Challenges in the Mini-Grid Sector in Africa: Lessons Learned from the EEP Portfolio. Hatfield (UK): EEP Africa; 2018.

35. Cantore N, Nussbaumer P, Wei M, Kammen DM. Promoting renewable energy and energy efficiency in Africa: a framework to evaluate employment generation and cost effectiveness. Environ Res Lett. 2017;12(3): 035008.

36. The Market Opportunity for Productive Use Leveraging Solar Energy (PULSE) in Sub-Saharan Africa. Washington, D.C. (US): International Finance Corporation; 2019.

37. Lenzen M, Kanemoto K, Moran D, Geschke A. Mapping the Structure of the World Economy. Environ Sci Technol. 2012;46(15):8374-81.

38. Wei M, Patadia S, Kammen DM. Putting renewables and energy efficiency to work: How many jobs can the clean energy industry generate in the US? Energy Policy. 2010;38(2):919-31.

39. Kammen DM, Kapadia K, Fripp M. Putting renewables to work: how many jobs can the clean energy industry generate? Berkeley (US): University of California; 2008. p. 28. 
40. Hussmanns R. Statistical definition of informal employment: Guidelines endorsed by the Seventeenth International Conference of Labour Statisticians. Presented at the 7th Meeting of the Expert Group on Informal Sector Statistics, 2004 Feb 2-4; New Delhi, India.

41. Mayer-Tasch L, Mukherjee M, Reiche K. Productive Use of Energy-PROUSE: Measuring Impacts of Electrification on Small and Micro-Enterprises in SubSaharan Africa. Bonn (Germany): GIZ; 2013.

42. Das BL, Baruah M. Employee Retention: A Review of Literature. IOSR J Bus Manag. 2013;14(2):8-16.

43. International Standard Classification of Occupations: Structure, group definitions and correspondence tables. Geneva (Switzerland): International Labour Organization; 2012.

44. East African Qualifications Framework for Higher Education. Arusha (Tanzania): East African Community; 2014.

45. Youth Definition. United Nations Educational, Scientific and Cultural Organization. Available from: http://www.unesco.org/new/en/social-andhuman-sciences/themes/youth/youth-definition/. Accessed 2019 Feb 18.

46. Global Off-Grid Solar Market Report: Semi-Annual Sales and Impact Data. January-June 2017. Utrecht (Netherlands): GOGLA; 2017.

47. Global Off-Grid Solar Market Report: Semi-Annual Sales and Impact Data. July-December 2017. Utrecht (Netherlands): GOGLA; 2018.

48. On-Site Solar is a Cost Saver and a Hedge on Energy Prices for African Businesses. New York (US): Bloomberg New Energy Finance; 2019.

49. Duby S, Engelmeier T. Kenya: The World's Microgrid Lab. Munich (Germany): TFE Consulting; 2017.

50. Mini-grid Investment Report: Scaling the Nigerian Market. Abuja (Nigeria): Nigerian Economic Summit Group and Rocky Mountain Institute; 2018.

51. Kenya Off-Grid Solar Access Project for Underserved Counties. Nairobi (Kenya): Lighting Africa; 2018.

52. Project Appraisal Document on a Proposed Credit in the Amount of 243.4 Million (US\$350 Million Equivalent) to the Federal Republic of Nigeria for the Nigeria Electrification Project. Washington, D.C. (US): The World Bank; 2018.

53. Productive use of off-grid solar: appliances and solar water pumps as drivers of growth. Utrecht (Netherlands): GOGLA; 2019.

54. Solar Water Pump Outlook 2019: Global Trends and Market Opportunities. Washington, DC (USA): Efficiency for Access Coalition; 2019.

55. Sustainable Energy for All Action Agenda (SE4ALL-AA). Abuja (Nigeria): Federal Republic of Nigeria; 2016.

56. Renner M, Garcia-Baños C, Nagpal D, Khalid A. Renewable Energy and JobsAnnual Review 2018. Abu Dhabi (United Arab Emirates): International Renewable Energy Agency; 2018.

57. Obala R. Kenya Power to review vendors' contracts amid customer uproar. The Standard. May-2018. Available from: https://www.standardmedia.co.ke/ article/2001279375/kenya-power-to-review-vendors-contracts-amid-customeruproar. Accessed 2019 Jun 4. 
58. Labour Force Statistics Vol. 2: Employment by Sector Report (Q3 2017). Abuja (Nigeria): Nigeria National Bureau of Statistics; 2018.

59. South Asia Economic Focus: Jobless Growth. Washington, D.C. (US): The World Bank; 2018.

60. Women and Men in the Informal Economy: A Statistical Picture. 3rd ed. Geneva (Switzerland): International Labour Organization; 2018.

61. Informal Enterprises in Kenya. Nairobi (Kenya): The World Bank Group; 2016.

62. Nigeria: Energy needs assessment and value chain analysis. Lagos (Nigeria): All On; 2017.

63. Clean energy powers local job growth in India. New York (US): Natural Resources Defense Council; 2015.

64. Global Wage Report 2018/19: What lies behind gender pay gaps. Geneva (Switzerland): International Labour Organization; 2018.

65. Monga C, Shimeles A, Woldemichael A. Creating Decent Jobs: Strategies, Policies and Instruments. Abidjan (Côte d'Ivoire): African Development Bank; 2019.

66. Renewable Energy Benefits: Leveraging Local Capacity for Solar PV. Abu Dhabi (United Arab Emirates): International Renewable Energy Agency; 2017.

67. Ferroukhi R, Renner M, García-Baños C, Barua B. Renewable energy: A gender perspective. Abu Dhabi (United Arab Emirates): International Renewable Energy Agency; 2019.

68. Baruah B. Renewable inequity? Women's employment in clean energy in industrialized, emerging and developing economies. Nat Resour Forum. 2016;41(1):18-29.

69. Winning the fight for female talent: How to gain the diversity edge through inclusive recruitment. London (UK): PwC; 2017.

70. Mini-Grid Training Needs Assessment: Gap Analysis for Developers. Goslar (Germany): Energy4Impact, Inensus; 2018.

71. Decentralized Renewables: From Promise to Progress. San Francisco (US): Power for All; 2017.

72. Khan S. Acumen Lean Data. Personal Phone Interview. 2019 Mar 12.

73. Powering Opportunity: the Economic Impact of Off-Grid Solar. Utrecht (Netherlands): GOGLA; 2018.

74. Smart Power India and Mlinda Foundation. Personal Phone Interview. 2019 Jun 15.

75. Hartung H, Pluschke L. The Benefits and Risks of Solar Powered Irrigation. Rome (Italy): Food and Agriculture Organization; 2018.

How to cite this article:

Shirley R, Lee C-J, Njoroge H, Odera S, Mwanzia P, Malo I, Dipo-Salami Y. Powering Jobs: The Employment Footprint of Decentralized Renewable Energy Technologies in Sub Saharan Africa. J Sustain Res. 2020;2(1):e200001. https://doi.org/10.20900/jsr20200001 